\title{
CHILDREN'S INQUIRY STRATEGIES \\ IN REFERENTIAL COMMUNICATION AND \\ IN THE GAME OF TWENTY QUESTIONS
}

CENTRE FOR NEWFOUNDLAND STUDIES

TOTAL OF 10 PAGES ONLY MAY BE XEROXED

(Without Author's Permission)

MARY LOUISE COURAGE 




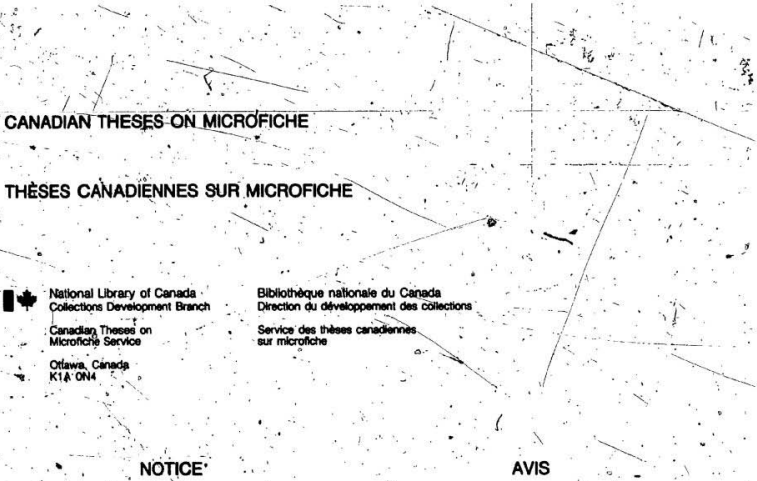

The quelity of this microfiche la teevity dependent upon the queity of the orighed thesis subfiltted for microfilming. Every effort hes been mide to enaure the highest quality of reproduct ton possible. fo

If peges are missing, contact the univeraity which granted the degree.

Some pages may, have indistinct print espectelly if the origined peces were typed with a poer typerwitter itibon or If the univer. sity sent us en inferior photocopy.

Previously copinghted materials voumal erticiea, publiahed lests, etc.) are not fímed.

Reproduction in full or in part of this film is govemied by the Canedlan Copyroht Act, R.S.C. 1970, c. C-30. Ploese reed the suthorization forms which accompeny this thesis.

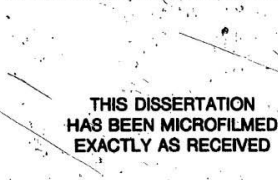

\section{LA THESE A ETE MICROFILMEE TEULE QUE NOUS L'AVONS REÇUE} $\rightarrow$

La quelite de cette microfiche depend grandement de la quallte de la these soumise au microfimeog. Nous avons tout feit pour assurer une qualtis supbrieure de reproduction.

SW mencrea des peoes, veullez communiquer evec Puniversith qui a conteré lo grade.

La qualit dimpression de certaines peges peut laisser a disetrer, surtout sil les peoses orlotnales ont et dectylographibes a l'edod d'un nuben use ou si runiveraite nous a fait parventr une photocople de qualite inferieure.

Lea dodiments qui font deja robjet d'un drolt d'euteur (erticles do revijo, oxaments publibs, etc.) ne sont pes microfimes.

Ln reproduction, mame pertielle, de ce microfilint est soumise a la Lo cendidieme our lo chott deuteur, SAC'1970, c. C-30.

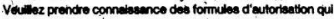
eccompeconent celte these.

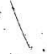




$$
\text { j }
$$

Abstract:

Young chlldren typlaally perform tnefficiently as ilsteners on referential communication tasks and also when playing the game of 20 , questions. In both cases they guess at the identity of the target rather than adopting the more efflclent strategy of asking categorlcal questions. Certain training procedures have been effective in improving. children's performance on both of these-tasks. An experiment was conducted to test the hypothesis that under certain conditions these two tasks can be considered as a single problem in information- seeking. It was prédicted: that if children were trained to use a strategy of asking categorical questions either in the context of a 20 questions task or a referential listener task, that performance on the trained task would Improve and would also 'generalize to the untrained task. Versions of the 20 questions and listener problems were designed in which the stimulus characteristics and information processing demands of the-tasks-were equated. 5- and 7-year-old male and fenale children were pretested on both tasks, trained either on the twenty questions task, the listener task, or given both types of training. A control group was given practice on the tasks. The treatment was followed by immediate and delayed posttesting on both tasks. Pretest performance was poor in both age groups, al though the older chlldren asked more categorical questions and identifled more targets 
correctly than did the younger children. Posttest data indloated a signifloant lmprovement in performance on the trained task, as well as substantlal cross-task general1= zation in both age groups. Except for the 5-year-old control subjects who showed very little improvenent from the pretest, there was 11,tle developmental difference in performance on the 20 questions task. On the listener task, only the 5-year-olds who experienced 20 Questions training performed as well as the 7 -year-olds on the posttests. It was concluded that 20 questions and ilatener problems car be " effectively solved with the common information-seeking strategy of asking categorical quéstions. 
Aoknowled géments

I would -1ike to express ny thanks to Dr. F. Michael Rabinow1tz for his guidance, encouragenent, and patience

织 during the course of this research. His supervision has. been extremely valuable to me." I also appreclate the advice " of Drs. John Strawbridge and Carole Peterson who served las, committee members.

I would also like to thank the office of Research at Memoriel University for the financial support provided in

3 the fopm of annual awards from the Vice-President's Grant

c for the Improvenent of Qualifications.

i $\therefore \quad$ I am also grateful to Ms.Geraldine Roe of the Roman Catholle School Board for St. John's; and to Ms: Dorothy An Snow and her Staff at Holy Cross Primary Schogl for their cooperation during this project. Finilly, thanks to the children at Holy Cross who served as subjects in this study. $\therefore \rightarrow$

$\underbrace{}_{a=}$


Introduction. . . . . .

Referential communfeation....................... 1

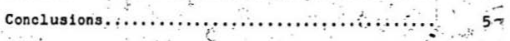

Metacomunfication $\ldots, \ldots \ldots \ldots \ldots \ldots \ldots \ldots \ldots \ldots, \quad 7$

Twenty questions $\ldots \ldots \ldots \ldots \ldots \ldots \ldots \ldots \ldots \ldots \ldots, 12$

Conclusions ........................... 17

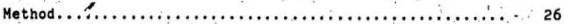

subjects $\ldots, \ldots \ldots \ldots \ldots \ldots \ldots \ldots, \ldots \ldots \ldots \ldots \ldots, 26$

Stimuli. . . . . . . . . . . . . .

Design and procedure $\ldots \ldots \ldots \ldots \ldots \ldots \ldots \ldots \ldots \ldots \ldots \ldots \ldots \ldots \ldots \ldots, 27$

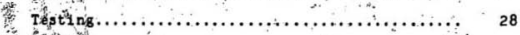

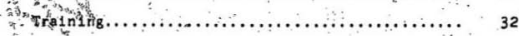

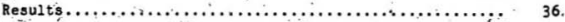

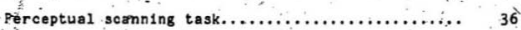

renty questions task $\ldots \ldots \ldots \ldots \ldots \ldots \ldots \ldots \ldots \ldots, \quad 38$

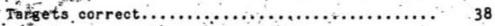

Type of questions asked..................... 40

Listener task.............................. 44

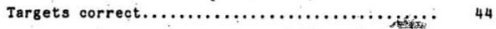

Categorical questions,..................... 47 


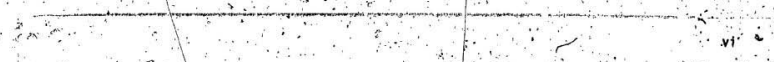

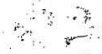

Dísoussion.

Perceptual scanning task.

Twenty questions and Istener

taskg

Conclusions.

Tables...

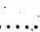

72

'References:
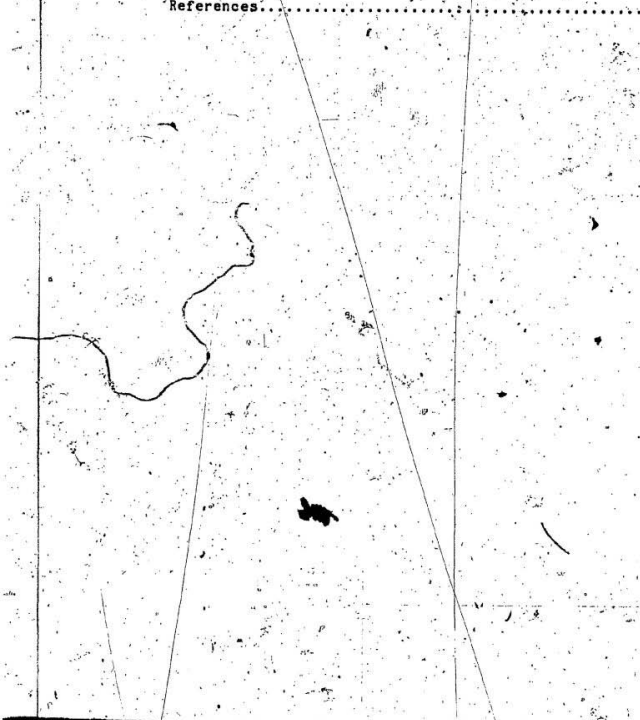

is. 
List of Tables

Table 1. Mean number of errors on the perceptual scanning task as a function of age, sex, and

\section{i number of targets cequired.}

Table 2. Mean number of errors in the perceptual scanning task as a function of the, phase. of testing and the number of targets required..

Table 3. Mean number of targets correctly ldentifled on the twenty questions task as a function of age, phase of testing and treatment condition.....

Table 4. Mgan number of categorical and single-item $+1$ questions asked on the twenty questions task.las a function of age, phiase of testing, and treatment condition

Table 5. Mean number of targets correctly Identifled on the listener task-as a function of the degree of ambigutty of the speaker's message, age, treatment condition, and phase of testing.

Table 6. Mean number of targets correctly ldentified on the listener task as a function of age, treatment condition, and phase of testing:

Table 7. Mean number of targets, correctly identifled on the 11stener task as a function of age, sex, phase of testing, and ambiguity of the speaker's message. 78 
Page

Table 8. Mean number of categorical questions psked on the listener task as a function of the ambiguity of the speaker's message, age, treatment, and phase of

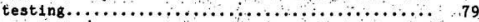

Table 9. Mean number of categórical questions asked on the of listener task as a function of age, sex, phase of testing, and amblguity of the speaker's message., 80

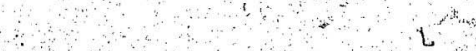

t.

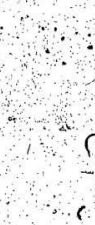

(4)

$\because$

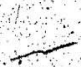




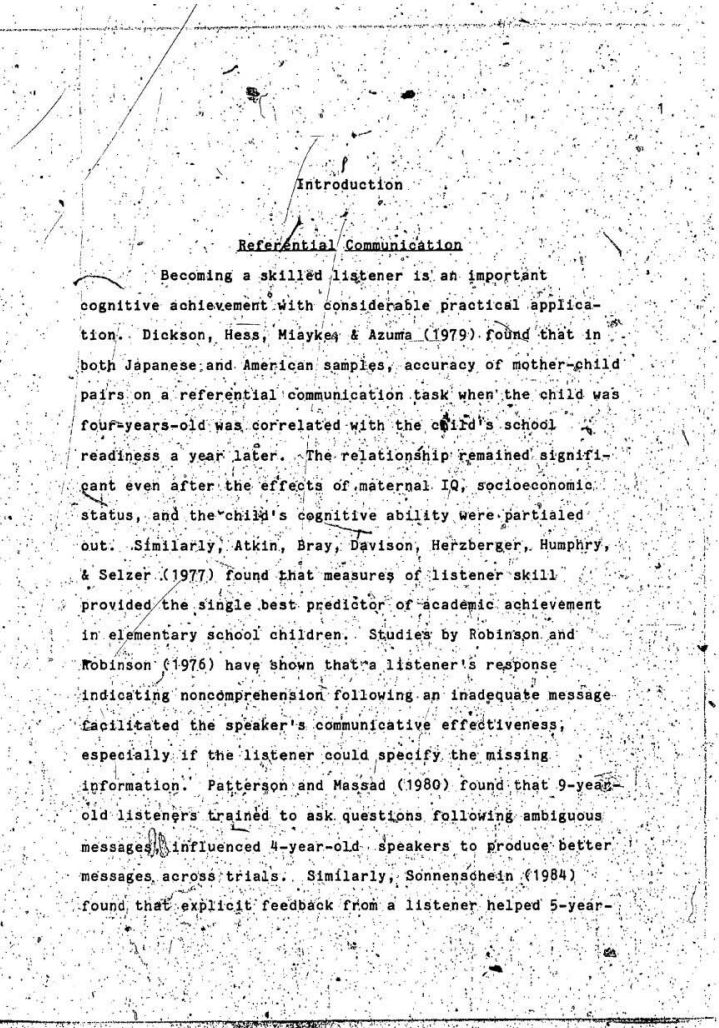


old chldren attend to message quality and improve their own speaker skills. Finaly, much of the child's school day is spent listening to classroon instruction. The effectiveness of this instruction will depend, in part, pn the child s listener skilis, It is important that children consider. communications/carefully, monstor their level of comprehension, recognize an inadequate riessage, as such, and realize that asking questions is the appropriate strategy to cope, with the problem of noncomprehension.

The early literature on listener skills presented a pessimistic ploture of young children's abilities with regard to these basle skills While they were generally able to correctly identify a referent following an adequate message, when given an inadequate nessage their performance was poor. For example, when preschool and kindergarten children were given refential hessages containing blatant Inadequacies, they seemed unable to detect these probliems, and selected a target, without seeking clariflcation. They behaved in this manner in spitg of the'speaker's warning that some of the messages were "bad" or "tricky" (Ashèr, 1976? Bearison \& \& Levy, 1977; Cosgrove \& Patterson, 1977 , 1978; Flavell, Speer, Green, \& August 1981/ Ironsmith \& Whitehurst, $1978 \mathrm{a}$, $1978 \mathrm{~b}$; Markman, 1977,1979 ; Mélssner, 1978; Patterson, O'Brien, Kister, Carter, \& Kotsonis, 1980 Robinson Robinson, 1976, 1977). The children's apparent 
inability to detect message ambiguities was attributed primarily to their fallure to complete the exhaustive comparison activities that the task required. Although dhildren were shown to have the ability to make these boparisons, they did not do so in the task s1tuations (A'sher, 1976; Ford \& Olsôn; 1975; Lempers \& Elrod, 1983; Robinson \& Robinson, T977; Whitehyrst \& Sonnensohe1n, 1981). children's message appraisal performancel is the response Another important factor which appears to affeot mode by which they express themselves. Most researchers require and record a child's verbal response There $1 \mathrm{~s}$ evidence that while children may fall to express verbaliy that a message is inadequate, an examination of a variety of nonverbal responses (eg. latency to respond, boty movenent,

- eye contact, puzzled facial expression) indicates that the child has detected at some level that there is a problem with the message. Several researchers have reported such discrepancies between verbal and nonverbal modes (Beal \& Flaveli, 1982; Bearison \& Levy, 1977; Flavell et al, 1981; Harris, Krulthof, Terwogt, \&.Visser, 1981; Ironsmith \& Whitehurst, ‘1978; Patterson et al, 1980).

Houng foildren also appeared to be deficient in

* giving feedback to the speaker following an inadequate message. Requests of the speaker for missing information are rare in preschool and primary school children and 
Increase over-the elementary school age range. (Alvy, 1968; Cosgrove \& Patterson, 1977, Dickson; $1974 ;$ Dittmah, 1972 ; Karabenek \& Miller, 1977 ; Markman, 1977, 1979; Melssner. 1975; Ironsm1th and Whitehurst, 1978). However, it appears. that a question-asking strategy can be trained in young children. Several studies have shown that children who were given such a "plan" for effective listening asked more questions, got more information, and made more correct, referent cholces than did control children who had not been. trained (Cosgrove \& Patterson, 19) 77 , 1978; Ironsmith \& Whitehurst, 19780, Patterson, Massad, \& Cosgrove, 1978; -Pratt \& Bates, 1982).

Thus, it appears that foung children do possess the competence, to give feedback. They haye been observed to give feedback to speakers following an inadequate message in naturalistic observation situations (Robinson \& Robinson; . 1977; Spilton \& Lee, 1977; Weliman \& Lempers, 1977), and question-asking can be elfcited with training.: However, they do not spontanegusly give feedback in the structured referential situation.

In sumary, task component analysts of children's iistener skilis indicated that they do have the basic skilis necessary to function as effective listener's They have, been observed to make comparisons momg stimuli, dẹtect ambiguities, and give feedback to speakers in a vartety of 
experitiental and naturalistic situations. However, it seemed that these, young children, were unable to coordinate these skills to perform effectively as listeners in the structured referential communieation task situation.

\section{Conclisions}

The inftial attempts to resolve the discrepancy between chlidren's competence and their performance; as 1steners involved strong criticism of the standard referential communicat1on task itself (Asher, 1979; Flavell, 1977; Fílavel1 et al, 1981; Whitehurst, 1981; Maratsos, 1973; Menig-Peterson, 1975; Whitehurst, 1981), Specifically, it. was asserted that the task is highly artificlal and lacking in relevance to the usual experience of young children. Furthermore, when child is in the listener, roĩe, he/she is put in the position of criticlzing an adult speaker. Young children may well be reluctant to do this, since they generaliy percelve adurts to be competent.

It was also argued that the standard task required more in the way of communication skili, than did more naturalistic, comminications. In everyday transactions, children-spend much of their time in communication with adults, who compensate for some of their deficiencles as issteners. For oxample, adults have been observed to provide simpler and more repetitlous messages when talking 
to a young ch1ld (Bohannan * Marquis, 1977; Robinson * Robinson, 1977; Snow, 1972; W1lcox \& Webster, 1977). Pratt and Bates (19822 discussed the importance of physical context in the development of young chlldren's communication. They noted that many of the studies showing limitations in listener performance have involved verbal messages out of physical context. Finally, many of the istener tasks of everyday 11 fe make fewer demands for comparison activity and word knowledge or vocabulary than did the standard referential task. Ackerman (1979) has argued that the listener task may not address a child's communicative competence as much as his/her ability to oonduct a perceptual analysis, of the referential field: - Shatz (1978) discussed the importance of information procesising variables such as memory and attentional capacity on children's communicative performance. She suggested that refetiential tasks which require recali rather than recognition measures, use large or multidimensional stimulus arrays, or involve unfantlar materials, place heavy information processing demands on young children.f This tends to degrade their performance on the tasks and results in an underestimation of their communicative competence. Several studies designed to test this if Information overload hypothesis have been supportive. When task demands are reduced, so that competence in exercising 
the basic component skilis can be examined, children perform effectively as listeners in referential communication situations (Lempers Elrod, 1983; Patterson et al, 1980; 1981 ; Pratt \& Bates, 1982; Robinson, 1981; Whitehurst \& Sonnenschein, 1981).

\section{Metacommunication}

Recent literature on the developinent of listener skilis reflects a different emphasis. It is suggested titat while young children have the basic component skills necessary for referential communication, what they lack is an understanding about communication itself, and an: awareness of the procedural rules for effective communication. Flavell (1977) refered to this aspect of knowledge as "metacommunication". Metacommunicative knowledge goes beyond having the basic component skills necessary for communication. It implies an awareness, on the part of the child that a certain situation requires referential communication, and that for this to occur effectively both 11stener and speaker are required to Interact in a reciprocal manner. Thus, the competent child recognizes communication as a dyadic enterprise, a relationship between speaker and istener around a task (Asher * Wigfield, 1978; Flavell et al, 1981; Robinson \& Robinson, 1982, 1983; Singer: \& Flavell, 1981;-Sonnenschein \& Whitehurst, $1983 ; 1984 \mathrm{a}$, 
1984b).

Research based on these assumptions indicates that several metacommunicative. skills âppear to be felevant to listener effectiveness. For example, children must understand that the message 1 tself is relevant to communication success or fallure, and that it must refer uniquely to whatever the speaker has in mind. Studies by Robinson and Robinson $(1976,1977,1978,1979,1981)$ have addressed these : 1ssues. They found that 5-year-old ch1ldren, acting alternately as speakers and listeners, lacked this understanding. They consistently blamed the listener for communication failure following an inadequate message. More mature communicators appropriately blamed the speaker following such a communication fallured. "Listener blamersit were also less likely to complete thè necessary comparison activities than were "speaker blamers". They seemed to Judge message adequacy on the basis of whether it fitted the referent, without considering the nonreferents. "Listener blamers" were also less well able to deliberately produce a poor-message upon request. Nor could they suggest ways in which a poor message could be improved. Recently; Whitehurst and Sonnenschein (19.84) showed that evaluative skilis such as those required in the Robinsons'. task, are later to develop than are the component sk111's required for competent listener performance. They concluded that chlld- 
ren can be competent 11steners without being able to evaluate a communication interaction.

Mature listeners must also understand that in a communication situation they should give appropriate feedback to the speaker, especially 1f. the message has been inadequate. Ideally, the reedback should be explicit in specifying the missing information. This requires some perspective-taking ability in that the listener must be able to infer what it is that the speaker needs to know in order to be able to modify the message. At a simpler level, the child should at least recognize that he/she should ask a $\rightarrow$ general question or otherwise express noncomprehensión. Although preschool children have been observed to give feedback to speakers in naturalistic situations (Robinson $\&$ : Robinson, 1978; Spilton \& Lee, 1977; Welman \& Lempers, 1977), they do not transfer the skill to the referential. task situation (Cosgrove \& Patterson; 1977; Ironsm1th \& Whitehurst, 1978). These children may not realize that a part their role as isteners in the referential task situation is to inform the speaker when a message has been inadequate.

Good ilsteners must also be able tomonitor trieir. own level of comprehension. Although it thas not been precisely defined, comprehension monitoring is seen as an executive process whereby an individual actikely keeps track 
of written or orally presented material, and becómes aware of his/her lack of understanding, should it occur. In researoh, the concept has been operationally defined as

Hask asking a question, or signaling the need for more information, following an inadequate message. It has been argued that failure to monitor comprehension is an important contributing factor in children's poor performance as l1steners (Markman, 1977; 1979; Flavell, Green, Speer, \& August, 1981). These researchers have stated that comprehension monitoring is late developing skill (or set of sk1lis) which presupposes the existence of other more basic listener skills. It is this executive process which coórdinates the component skills into effective listener perfodrmance.

* Others have-argued that young chlldren do have the ability to moniţor their comprehension. Shatz (1978) said that if the information processing demands of $a$ communication task were minimized, then young listeners would have more ressources avallable to engage in comprehension monitoring. As discussed above, recent research conducted to testi this 1dea has been supgortive. When task demands are sliniplified, preschoolers do ask for more information following inadequate messages (Patterson, O'Brien, Kister, Carter, \& Kotsonis, 1981; Pratt \& Bates, 1982). 
It would appear then, that asking questions is a critical listener skili in the referential communication task situation. It indicates that the child is monitoring his/her level of comprehension. It gives the speaker the essential feedback needed to modify the message. Aṣking questions, may be the missing component which prevents the child from furictioning as an 'effective listener in this situation. However, faflure to ask questions might not mean that the child did not monttor his/her comprehension. It might be that the child does not realize that asking; questions is the appropriate strategy in the situation.' Researchers have found that the most effective 11stener training programs are those which emphasize the acquisition of a question-asking rule. Children of primary schiool age who did not spontaneously question a speaker following an Inadequate message did so when they were given a "plan" for effective listening: which emphasized the Importance of asking questions as the only way to find the correct referent when the message has been unclear. In this: way, young children who made comparisons among referents and detected ambiguities, became aware of how to act in the referential situation (Cosgrove \& Patterson, 1977, 1978; Ironsmith \& Wh1tehurst, 1978; Patterson \& Kister, 1981; Patterson \& Massad, \& Cosgrove, 1978; Patterson \& Massad, 1980)'. 


\section{Twenty ovestions}

Flavell (1977), referred to the referential task as a communication problem which young 11 steners.are required to solve. Specifically, the proplem requires that they identify a target referent on the basis of a speaker's verbal message. When the message, 1s unambiguous, chtldren can solve the problem readily. However, when the information given is unclear, the immature 11 ftener will select a target by guessing. The mature 11stener will request additional informatión. To get additional informa tion most efficiently, the listener should specify the nature: of the needed information precisely. Thus, solving communication problens requires that children ask informative questions. Researchers have found that the type of questions children ask changes. with age. Preschool children rafely ask any questions at all in a réferential, task situation, al though they give nonverbal signs of puzzlement. When children do befon to question a speaker following an Inadequate message, they do so by making general statements or by asking general questions ("I don't know which one you mean."). Over the age range from kindergarten to fourth, grade, children's questions become lessmieneral and, more specific or categorical (e.8. "Is it large or small?") (Cosgrove \& Patterson, 1977; Ironsmith \& Whitehurst, 1978;<smiles>[CH]</smiles> 
categorical-question model. The older children, aged 9-, 11-, and 13-years did ask more categorical questions under these circumstances. However, only the children in the two older groups showed any Improvement in problem-solving efficlency along with their increase in categorfical questions. Problex-solving efficiency was;opedationally defined a's the nifiber of questions that the child asked before being abiesto identify the target stimtaus.

A different approach to the modification of question-asking strategies has been to expose children to "cognitive" or "strategy" models who (a) lverbally demonstrate how to classify similar stimuli. into categories, (b) exemplify categorioal questions based on such classification, and (3) verbally indicate how to use the inforination received as the result of the question-asking (Denney, Denney, \& iobrowsk1, 1973; Denney \& Denney, 1.974 ; Denney, 1975). These researchers found that exposure to strategy models increased the categorical questions asked by chlldren from 6- to 8-years old. Thus, strategy modeling seemed to be more effective with children at the beginning of the transition in question-asking as defined by Mosher and Hornsby (1966). However, accompany ing, Increases in problem-solving efficlehcy anong these young children were not always observed. For chlldren at the upper end of the transition peryod, both exemplary and strategy models are 
effective in impróving problem-solving efficiency.

Denney and Connors ( 1974$)$ modified the intèrrogative strategies of preschoolers by testing them with a slight ly different version of the standard 20 Questions task. Instea of using visual stimulus arrays, categories were determined by the experimenter ("I am thinking of a type of food. "). It was belleved that this type of stimulus material would force the childrén to ask.

categorical questions because of the potentially large size of the array. Further, that ance the array was not physilcaliy present, childreh would be discouraged from simply naming the stimuil Children were exposed to either atrategy or exemplary models in this manner. on the first posttest, in whioh the stimulus Items yere the same as those used In training, chllaren in both modeling conditions asked more categor ical questions, and requi red fewer questions for solution, than did control children who were not trained. However, on the second posttest, which used different stimulus items, on 1 y ohildren who had been exposed to the strategy model asked more oategorical questions and were more efficient problem-solvers:

Denney, Jones, and Krigel (1979), Investigated the effect of yarious strategy iodeling variables-on the performanca of 6-year-olds Chlidren were asolgned to one

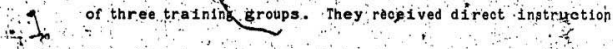




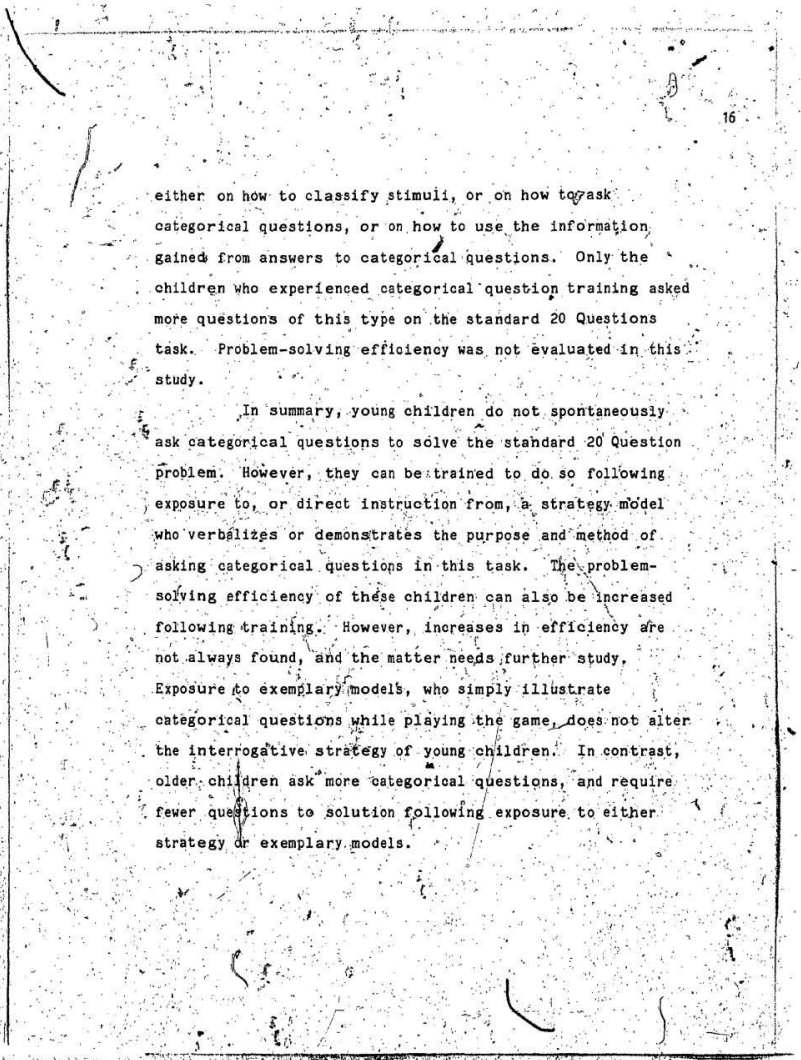


$\therefore \quad \therefore, \%$

\section{Cenclusions}

Although it has not been the focus of the research - discussed above, it could be argued that the task of the 1s istener in referential communication and the task of the player in 20 Questions are comparable. The goal is the same in each case. The subject must identify a target stimulus from an array of items. In both cases this is most." efficiently done by asking the speaker categorical questions which enable the child fo narrow in on the target quickly. In much of the existing research however, a child is considered to have responded correctly on a listener task if he/she merely indicates that the méssage has not been understood. No questions are required. While indicating ,

* noncomprehension is an adequate response, communication is most efficlent whes the Iistener can provide the speaker with explicit feedrack about the nature of the missing information. This can be achieved effectively by asking categorical questions. Another similarity between the 20 Qúestions and 11sterierltasks is that young children of primary school age adopt a similar strategy in both of these task situations. When the target is not immediately

apparent they guess 1 ts identity. older children will adopt the more efficientstrategy of asking categorical questions to get more information, or to eliminate ltems or referent $\mathrm{s}^{\prime}$ before identify ing the target. 
The two tasks also requitemany of the sathe cognitive or information processing skills , Consider the following analy's of the steps required of an efficient. subject in acase in which the two tasks are identicaly Such 1dentity exists between the requirements of a modified version of the 20 Questions task, and the task of a listener following a speaker's uninformative message. In neither of these cases is the subject given useful information on the first trial. Suppose that the subject is presented with a simple stimulus array of four items which vary from eqach other along two dimensions: An example would bé a large brue square, a large red square, a small blue square, and a - small red squarg Under 20 Questions instructions the child should procede as foliows:

Step r. Scan the stimulus array.

Step 2. Categorize the stimuli into two groups.

Ștep 3. Ask,question 1: Is it blüe? (Answer:Yes.)

Step 4. Scan the remaloning tems in the array.

Step 5. Gategorize the rotimulif into two, groups:

Step 6. Ask question 2: Is it large? (Answer Yes.)

Step 7. Identify the target with question" 3

In Instances where the child gets a negative responset to a question, the minimum number of questions needed, for

Colution does not change, However, the child will need to. perform an additional operation of the type "If not A, then

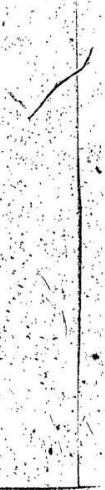


B: " and store this 1nformation in memory.

When presented with the same stimulus array and an uninformative message ("fit's a square" ); in a referential communication task context, the listener should procede as rolious:

Step 1. Scan tha stimulus array.

Step 2. Categorize the stimult into two groups. Step. 3 . Ak question 1 Is lt red of blue? (Ánswer: Blue.)

Step 4 , Scan the remaining 1 tems in the array. Step 5. Categorizel the stimuli into two groups. step 6. Ask question 2: Is it large or small? (Answer : Large.)

Step 7. Identify the referent with question 3. However, when the listener starțs with a partiy. informative message ("Itars biue.") or a fully informative message. ("Itt"s large and blue. in), his/her task is clearly simpler and fewer of the stêps described above will be requilrëd to ldentify the target.

Although there are-sindiarities between the requirements for the of elerential and 20 Question tasks, there ạre also some notable differences between them In the example discussed above, the chlld"playing the modtfied versfor of the 20 questions task must be able to use the information provided by "no" answer., He/she must be ablé 
to understand the logical operation "If ngt then B.", and use the information derived-to eliminate nombarget stimuli: This operation is not a part of the listener's task in referential communication, since the child is always told what the target is, rather than what it is not:

Considering the existing literature, another point of difference is that across a series of trials the listener in referential, communication is generally given more. information to work with than is the subject playing. 20 Questions. While speakers do give uninformative messages on some trials, they also sivie partiy or fully informative messages on other trials. In 20 Questions the chlid begins with no Information other than that which is provided by the stimulus array, and must soliclt all the information by asking questions.

In addition, most of the researchers who have studied, the 20 Questions problem. have used the standard 42 1 tem stimulus array. This version of the task requires more scanning, categorizing and use of memory than do apy of the listener tasks that researchers in referential communiogtion have reported using:

A final point of difference involves the requirement of making comparisons among stimuli in ther array. In the 20 Questions task the efficient player must scan all of the items in the array before forming a 
hypothesis about the 1dentity of the correct target. In the referential task, in which the speaker gives the listener some Information-about the identity of the target, the ahild also has to scan the array in order to find a match. In addition, the listener has to be able to detect any ambiguity in the message, for example, the presence of more than one item that fits the speaker's description. This requires the child to compare each stimulus item with his/her memory representation of the speaker's message. It has been suggested that an important reason iwhy children fall to function as effective 11 steners ahd 1nstiead aake incorrect choices, is because they don't complete the necessary comparison process. Rather, the child f's likely to conduct an incomplete search which ends with the identffication of the first appropriate match (Asher, 1968, 1979; Asher \& Parke, 1975, Bearison \& Levy, 1977; Ford \& Olson, 1975; Robinson \& Robinson, 1976, Whitehurst \& Merkur, 1977; Whitehurst \& Sonnenschein, 1978). It is possible that the necessity of checking for a match between the characteristios of the message and, the 1 tems in the stimulus arfay could make the listener taska more difficult one for young children.

$$
\text { Considering these points of difference between the }
$$
two tasks 1t might be expeoted that the referential communication problem would be an easier oné for young 
chilidren to solve, In many ways it is less demanding. However, it is not glear that this is so. While young children do not' pecform efficiently on either task without training, researchers seem to have had more success in training children on the 20 Question task. While there are no studies which have compared performance on the two problems directly, there are some data whlch tend to support this possibility. For example, preschoolers ask more categorical questions and solve the 20 Question's problem more efficiently following appropriate training. In contrast, on the ilstener task, while ohildren across grades one to four show significant improvement in question-asking. following appropilate training, only the older children in this age range ask more categorical questions. Preschoolers and kindérgarten age chlldren are more difficult to train in the question-asking-strategy; and the results are mixed Flironsmith \& Whitehurst, $1978 \mathrm{~b}$, Patterson et al, 1978, 1981).

\% The reason for this discrepency is not clearr. It may be that the 20 Question problem has more task relevance?: for the young children. Their role in the situation is not one of criticizing the adult speaker, but one of seeking clues to the solution of a game. It may be more obvious to the child that his/her task is to ask questions: (.. An important explanation pay lie in the different 
way that a trial is defined in the two tasks. In the 20 Questions probiem a trial begins when the childrasks the 2.

first question, and ends after the target has been identified or 20 questions have been asked, whichever occurs. first. The dependent variables of interest are the number and type or questions asked. On the referential communication problem a trial begins when the listener asks the first question, but ends when the first target is selected. If the cholce is correot, the child is scored as right, if it is incorrect, the child is scored as wrong and a new trial begins. If trials and dependent measures vere equated In these two tasks children's performance may be more comparable.

Finally, it is also possible that, as discussed above, young I1steners may be unable to detect message ambiguity because they fall to complete the necessary comparison process which requires them to match each 1tem in the array with their memory of the speaker's message. Thus, the listener task may genuinely be more difficult for young children. The first hypothesis of this study was formulated to test the potential importance of this problem in the listener task. If children were unable to search and compare exhaustively, then it could be, argued that detecting ambiguity is an additional cognitive requirement that would make the listener task different from, and more difficult. 
than the 20 Questions task. To test this possibility, children were given a perceptual scanning task in which they were required to scan a stimulus array in search of a vairied number of targets which had certain specified character1stics. It was predicted that children would be able to conduct an exhaustive search of a stimulus array and thus perform competently.

The primary purpose of this study was to investigate the relationship between ohildren's inquiry strategies as isteners in referential, communication, and their inquiry $i$ strategies in the game of 20 Questions. While these two tasks can be considered as logically.similar, they have. always been studied independently. Furthermore, researchers In each of these areas have drawn different conclusions about children's ability to ask questions. The basic hypothesis that this study was designed to test was that if the information processing and task demands of the 20 Questions and referential listener problems were equated, then both of these tasks could be reduced to a single problem in information seeking.. It was predicted that if children were trained in the strategy of asking categorical questions either in the context of a 20 Questions task or a referential listener task, that performance would improve on the trained task, and would also generalize to performance on the other task. 


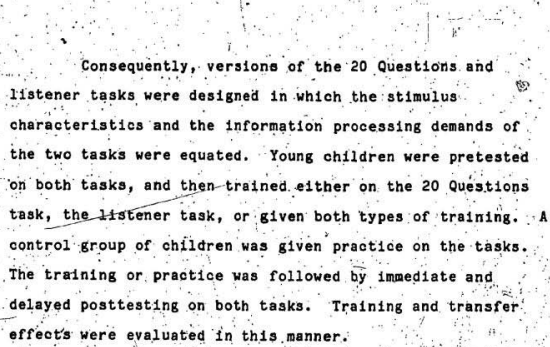
characteristics and the information processing demands of the two tasks were equated. Young children were pretested on both tasks, and then-trained.either on the 20 Questions task, the distener task, or given both types of training. A control group of children was given practice on the tasks. The training or practice was followed by immediate and delayed posttesting on both tasks. Training and transfer effects were evaluated in this manner: 
Hethod

\section{Subjects}

The subjects consisted of 32 boys and $32 \mathrm{~g} 1 \mathrm{rls}$ aged, 5-years-old (mean age 5 years 8 months), and 32 boys, and $32 \mathrm{girls}$ aged 7 -years-old (mean age 7 years 5 months). They were selected from kindergarten and grade two classes of a local primary school. Permission to conduct the study was obtained from the school board concerned, and from the parents of the children. Data from ten additional 7-yearold children were eliminated from the study, following perfect performance on the pretests. Data from another ten of the 5-year-old children who did not want to participate in the study were aiso eliminated.

\section{stimulit}

Eleven, elght-1tem stimulus arrays were used to evaluate both 20 Questions and ilstener performance. Each array consisted of elght ifne drawings of a common object. The drawings ín each array var ted systematicaliy along three dimensions. Each dimension was represented by two values. An example set nould be: a house whlch is /either red or blue, with or without a door, with or without windows. Three of the arrays were used in the perceptual scanning task. Two of the arrays were used during pretest, two for 
Iminediate posttesting, and two during delayed postresting. The final two arrays were used in'training: Selection of the particular arrays to be used on the scanning task,

1. during training, and at each of the three phases of testing was randonized for each subject:

Besian and Precedure

An ABe (5 years, 7 years) $x$ Sex $x$ Treatment (Listener, 20 Questions, tisteker and 20 Questions, notraining control) × Phase (pretest, immediate posttest, delayed posttest) factorial design was used. The first three factors were between-subjects, and the fourth was within-subjects.

Subjects were quasi-randomly assigned to one of the four training conditions such that age and sex were counterbalanced acrosss training conditions. Thus, a cell consisted of elght children of the same sex and age who experienced the same training procedure.

Each subject was seen individualiy on two occasions. On the flrst day he/she was pretested, trained, and $\mathrm{g}$ iven an immediate posttest. One week later a delayed posttest was given. Before the pretest and the posttests, subjects were given the perceptual scanning task. The purpose of this task was to check whether the children would scan a stimulus array exhaustively, while searching for 
certain specified targets. Thus, the child was shown ane of the arrays and instructed to point to the pictures on the array which 11lustrated certain features and combinations of. features as specified in a speaker's message. The children were given four méssages. which varled in the number of stimulus characteristics specified on each of the four trials. Accordingly, the child had to Identify either one, two, four, or elght of the items on the array. A scanning. error was recorded if the child included a target that did not fit the message, or excluded an 1 tem which did fit the message.

Following the scanning task, the subject was given one 20 Questions problem and five listener skills problems. The order in which the two tasks was given on each of the three tests was counterbalanced across subjects in a cell,f such that each of the subjects experienced a different combination of the efght posslble counterbalanced orderings. An example of one of the possplole orderings is: 20 Questions followed byolistener on the pretest, listener followed by 20 Que'stions on the immediate posttest, and listener followed by: 20 Questions on the delayed posttest:

Iesting, Instructions to the subjects performing the 20 Questions task were as follows:

"We are going to -play a question-asking game. I will think of one of these, pictures and it is your job to 
find out which one. The way to find out is by asking questions which I can answer "yes" or "no" -any question at all as long as. I can answer "yes" or "no". So you try to figure, out which picture I am thinking about by asking questions. You have eight questions to get the ariswer, but try to ask as few possible."

In order to avoid reinforcing guesses, the child was told a choice was correct anly if the other seven possibilities had been logicaliy eliminated. This could occur in a minimum of four responses if the child used the strategy of asking categorical questions, and efficiently used the information gained from the questions. An example. of four such questions would be: Is it blue? Does it have a door? Does it have windows? Is it the blue house with a door: and windows? In order to minimize the information processing load on the child, all categorical questions were answered "yes," by the experimenter, provided that they were consistent with previous chólces. This practice was followed for the listener task as well. The child was: allowed a maximum of elght questions. - If the target had not been Identified by this time, he/she was told the correct answer. The dependent meâsures were the type of question asked (single item or categorical), and whether or not tffer target was identified correctly.

Instructions to the subject performing the 
1stener task were as follows:

"Now we are going to play a listening game. We each have a set of pictures that are the same. Here's how we w1ll play. I will tell you about one of my pictures. I w11l call it the "special one". Your job is to find the. special picture that I am talking about. Sometimes I won't tell you enough about the special picture and you won't kfow which one I mean: If that happens and you can't teli which one I mean, you can ask me questions to help you find-the special picture, if

The child was questioned to make sure that he/she knew that questions were permissible. One practice trial was given to insure that the child understood what was expedted of him/her. Of the practice trial the efilld was given a partly informative message which gave information about one of the three dimensions (e.g. "It's a house with windows." If he/she asked a categorical question 1 it was answered directly. If he/she asked a singre-iteg question or selected a target without seeking clarification, the experimenter explained that only one picture was correct, and since there were several which could fit the speaker's description (These were illustrdted), hè/shie had to ask questions to get more information. Following the practice trial the subject doing the listener task was given four additional listener trials without explicit feedback. The 
same stimulus array was used on all 5 trials. Each trial began wlth the speaker giving the listener a new message. The messages given by the speaker varied in informational adequacy as follows: Set 1 was accompanied by a fully. informative message which gave information about all three dimensions le. $\mathrm{g}$ "It's a blue house with a door, but no windows."). Set 2 was accompanied by a partly informative. message which dave information about two of the dimensions (e.s,atits!s a blue house, with a door"). Set 3 was accompanied by another partly informative message which gave information about ore dimension (e.g. "It's a blue house. a). Set 4-was accompanied by an uninformative message which gave no useful information (eg. "It!s a house."). The order in : which these sets were presented to the child wa's randomized for each subject on. each test:

The speaker answered any categorical questions 4 that the child asked. In order to avoid reinforcing guessing, the child was told that a choice was correct only if the other logical possibilities had ben eliminated. The number of possibilities depended, of course, on the degree of adequacy of the message presented to the child. If the chlid asked a single-1tem question, and thus took a guess. without seeking clarification, the speaker responded "That's wròng. Let's try another one."

The dependent measures of Interest were the type 
of questions that the child asked (single-item or categorical), and whether or not the child selected the correct 'target referent.

- Araining. After pretesting, thie subjeọts éxperlenced ofie of the following four types of training: 20 Questions, Listener, both 20 Questions and L1sterier or notrainfing control

- Participants in the 20 Question training were taught to ask categoricai questions as the riost efficient way to identify the target: They werê given the following instructions:

"Those were hard games, weren't- they? You did well, but now I am golng to show fyou a way that w1ll help you to do even better: Let's go back to the question-asking game. This is what you should do, Whenever you ask a question, try to think of one that will tell you about more than one picture at a time. Don't just take a guess. "Try to figure it out. For example, you could ask if the thouse 1s:blue. If I say "yes", then that tells you about four of the houses doesn't it? You know that the house is a blue one. Thep you could ask me if 1 tos got a door. That telis you about two of the houses that are left. If I say. "yes", then you khow that the house is biue and has a door. Next, you couid ask me If the house has; any windows. If I say I "yes"; thep-yoll can figure out the answer. You know-that 
It's a blue house with a door and windows, Remember, you haye to figure/out the one 'I'm thinking about by asking good questions. 'Go ahẹad and ask me a question. "If the child asked an single-1ten question (1.ej, guessed) the experimenter explained agaín how to ask catégorical questions emphasizing,"Don't'just guess, try to figure it out. i The subject was guided through eight trials in this manner.

Participants in the listerier training were taught that the best strategy to cope with an uninformative or a partiy informative message is to ask categorical questions to clarify the ambiguity. They were given the following instructionsia "Those were hard gamés weren!t they? You did very, well, but now. I am going to show you a way to do even better. Lét's Bo back to the listening ganje. I will tell you about the special picture jưst like I did before:

Sometimes I won't tell you enough about the picture arid you won't know which one I mean. So be sure to take your time and look carefully at all of the plctures, If you can't tell which one is the special one because I didn't tell you enough about it, you know that it's time to ask a question iso you know how to find the special picture." Let me tell you how to ask sope bood questions. Whenever you ask a question, try to think or one that will tell you about more than one picture at a time. Don't ijust take a guess, try to I1gure $1 t^{\text {out }}$ For, example, you could ask if the house fs 
blue. If I say "yes", then that tells you about four of the pletures, doesn't it? You kriow that the house is a blue one. Then you could ask me if $1 \mathrm{t}$ has a door. That telis you about two of the pictures that are left. If I say "yes", -

then you know that the house is blue and has a door. Next, you could ask me if the howse has any windows. If I say nyes", then you can figure out the answer. You know it's a blue house with a door and windows, Let's see how well you dan do. Remember, the trick is ato ask good questions that will help you to find the special picture"

The chlidren were, given corrective feedback on all eight of the training trials. When the child selected the correct target following an informative message he/she was told: "Very good. You found the spectal plcture." Following a partly informative or an uninformative message the child should begin to ask questions to seek more information." If hé/she asked a single-item question" the speaker said "There" are tio (or four, or seven) other pictures that could also be right. I didn't teli you enough about the spectal picture, did I? I gave you a tricky message. I think you were guessing. Don't forget to ask me questions if you need help to flnd the special picture, ". If the child began to ask categorical questions they were answered so that the last 'logical cholce was correct. The speaker's message varled in informational adequacy. Since a message could give 
Information about three, two, one, or nohe of the stimulus dimensions, each subject experienced two of each type. The order of message types was randomized for each subject (in blocks of four)."

Participants in the combined 20 Questions/Listener training received both types of training as described above. They were 81 ven four trials of listener training and four trials of 20 questions training. The order of training and type of stimulus set was counterbalanced.

Subjects in the no-training control group were given eight practice trials either on the 20 Questions task or on the listener task : They were alternately assigned to one or the other practice group according to the order of their placement in that group. Age and sex of the subject were balanced in each" practice group. No corrective feedback was given. 


\section{Results}

\section{Perceptual Scanning Task}

At the beginning of each phase of testing, subjects were given a scanning task. The reason for Including this task. was to test each child's ability to make an exhaustive sedrch of a stimulus array, while attempting to locate certain 1tems in the array. which had been described in a speaker's message. The speaker's message varied in the humber $p^{f}$ stimulus characteristics that were specifled on each of the four trials. Accordingly, the child might have to indicate one, two, four, or elght targets on any given trial. A scanning error was recorded 1f the child included a target which did not fit the speaker's description, or excluded a target which didfit the speaker's descriptjon.

A 2 (Age) $\times 4$ (Treatment Condition) $\times 2($ Sex $) \times$ 3 (Phase of Testlng) $x$ 4(Number of Targts) analysis of yariance was performed on the scanning error data: The analysis revealed a significant interaction of Age $x$ Sex $x$ Number of Targets, $F(3,672)=3.69, p<.05$, wh1ch was higher order to the significant main effeots of sex, $F(1,112)=$ $4.61, p<.05$, and number of targets, $F(3,336)=3.25, p<.05$. Inspection of the data in Table 1 indicates that the number of scanning errors for all of the chlldren was extremely 
10w. In general, female subjects at both age levels had lower error scores than did the male subjects. The 5-yearold males made most errors wheh they had to identify one or two targets on the basis of the speaker's message. Among the 7-year-old males, most errors were made when they had to identify eight of the targets, following the speaker's message. However, the higher error rate in this age group was largely the result of the poor performance of two boy's who did not appear to understand the instructions. The analysis also revealed a significant main effect of phase of testing, $F(2,224)=5.03$, p<.01 In general, children reduced the number, of errors they made from the pretest to the posttests. However, this main effect was lower order to a significant Phase of Testing $x$. - Number of Targets interaction, $F(6,672)=2.48, p<.05$. The data in Table 2 indicate that in general, children reduced their error scores from the pretest to the posittests. They appeared to have most difficulty with the task on the prete'st when the speaker's message required them to identify all elght of the targets or only one of the targets. It is possible that the instructions ("Point to all the pictures that show...") may have confused them on these trials, and set an expectation that they should identify less than elght, or more than one or the targets.

In sumary, scanning errors in all treatment 
conditions, and at both age levels were infrequent. For the 7-year-old subjects 82.8 of the scanning trials were without error, and for the 5-year-old subjects $76 \%$ of the scanning trials were without error. This indicates that when children were asked to identify target stimull with specified characteristics they were exhaustive in their search of the stimulus array. Children checked each item in the stimulus array for a potential match rather than terminating their search after the first appropriate target i had been located.

20 Questions Iask.

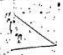

Targets cerrect. The mean number of targets correctly identified on each of the modified 20 Questions: tasks are presented in Tabje 3 . On each of these tasks the subjeot was presented with an eight-item stimulus árray and asked to try and 1dentify the item the speaker had in gind; by askirig questions. A maximum of elght questions was allowed. A 2 (Age) $\times 4$ (Treatment Conditíon) $x 2$ (Sex) $x$ 3 (Phase of Testing) analysis of variance was perforaed on these data. The analysis revealed a sifgnificant interaction of Age $x$ Treatment Cond1tion $x$ Phase of Testing, $F(6,224)=$ 4.29 , p<.001, which was higher order to the significant main effects of age, $F(1,112)=35.68$; $p<.001$; treatment condition $F(3,112)=11.63, p<.001$, and phase of besting 
$F(2,224)=168.94, p<.001$, and the interactions of Age $x$ Treatiment Conditon, $F(3,112)=4.48, p<.01$, and Treatment Condition $x$ Phase of Testing, $F(6,224)=5.98, p<.001$.

Inspection of the data in Table 3 reveals that the main effect of phase of testing : is interpretable. Subjects in all groups Increased their targets-correct scores from the pretest to the first posttest. In order to clarify the Age $x$ Treatment Condition $x$ Phase of Testing interaction, separate analyses of varlance were carried out on the pretest ard posttest data. Age and treatment condition were

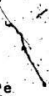

factors in both analyses. Phase of testing was also a variable in the posttest analysis: Only the main effect of: age, $F(1,112)=22.51, p<.001$, was significant in the pretest analysis. The 7-year-olds identified more targets correct than d1d the 5-year-olds. Analysis of the posttest data revealed a significant Age $x$. Treatment Condition Interaction $F(3,112)=7.97, p<.001$, which was higher order to the significant main effects of age $F(1,112)=15.72$, $p<.001$, and treatment condition $F(3,112)=16.15, p<.001$. There were no significant contrast effects involving the phase of testing variable. Posttest averages are presented in Table 3. The significant interaction reflects the fact that the 5-year-old ohlldren in the three experimental groups performed almost as well as the 7 -year-old onlidren. However, 5-year-old ohtldren in the control group were 


\section{5}

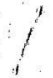

40

significantly poorer than the 7-year-old children, $F(1,112=$ 189.11, p(.001). It seems that the younger, children require training to substantially' fmprove their targets-correct scores, whereas practice is sufficient for the older ohildren.

Type of questions asked. The data on the number

of categorical versus single-1tem questions assked while performing the 20 Questions tasks are presented in Table 4. A categorical question is one which eliminated more than one alternative from the array of possible targets. A singleitem question is one which eliminated one 1 tem only from the array. A 2 (Age) $\times 4$ (Treatment Condition) $x$. 2 (Sex) $\times 3$ (Phase of Testing) $x$ 2(Type of Question) analysis of variance vas performed on these data. This anaiysis indicated a significant interaction of Age $x$ Treatment Coridition $x$-Phase of Testing $x$ Type of Question, $F(6,224)=15.080, p<0001$, which was higher order to the significant main effects of age; $F(1,112)=28.92, p<.001$, treatment condition, $F(3,112)$ $y=8.36$, proor, phase of testing, $F(2,224)=164.03, p<.001$, and type of question, $F(1,112)=57.09, p<.001$, and the significant interactions of Treatment Condition $x$ Phase of Testing $x$ Type of Question, $F(6,224)=5.42, p<, 001$, Phase of Testing $x$ Type of Question, $F(2,224)=194.33, p<.001$, Age $\times$ Treatment condition $\times$ Type of Question, $F(3,11 z)=$ 3.07, p<.05, Age $\times$ Type of Question, $F(1,112)=40.83$, 
W.001, Treatment Condition $x$ Type of Question, $F(3,112)=$ 9. $]^{4}$, p<.001, Age $\times$ Treatment Condition $x$ Phase of Tésting, $F(6,224)=3.28, p<.01$ Treatment Condition $x$. Phase of Testing, $F(6,224)=5.24, p<001$, and Age $\times$ Treatment Condition, $F(3,112)=2.92$, p<.05.

The data shown in Table 4 reflect the fact that. subjects in all groups tended to increase the number of categorlcal questions and decrease the number of single-iten questions they asked from the pretest to the immediate and delayed postests. This pattern of response reflects an Ancrease in efflciency in solving the 20 Questions problem. Categorical questions enable the child to eliminate more non-targets than do single-item questions and, thus, narrow in on the correct target with fewer questions.

(In order to clarify the Age $x$ Treatment Condition * Phase- of Testing $\times$ Type of Question interadtion; separate. lanalyses of varlance were conducted on the pretest and posttest data, Age, treatment, condition, and type of question weré factors in both analyses. Phase of testing was also a yarlabie in the posttest antalysis. The analysis of the pretest data reveaied significant main effects of age, $F(1,112)=18.86, p<.001$, and type of question, $F(1,112)=215.78, p<.001$, However, these can only be interpreted with reference, to the significant age $x$ Type of Question interaction, $F(1,112)=21.06$, p<:001. Inspection 
of the data ind1cates that on the pretest measure; 7-yearold children asked more categorical and fewer single-item questions than did the 5-year-olds.

Analysis of the posttest data indicated that, as was the case with the target data, there were no significant contrast effects involving the phase of testing variable. T The posttest averages are presented in Table: 4. They. analysis did indicate a significant interaction of Age $x$ Treatment Cond1tion $x$ Type of Question, $F(3,112)=6.31$, PS.001, which was higher order to the significant main. Jeffects of age, $F(1,112)=12.35, \quad p<.001$, and treatment - B condition, $F(3,1,12)=12.20, p<.001$, and the isignificant Interactions of Age $x$ Type of Question, $F(1,112)=20.98: \therefore$ $p<.001$, Age $x$ Treatment Condition $F(3,112)=5.15, p<.01$, and Treatment Condition $x$ Type of Question, $F(3,112) \rightarrow$ $12.78, \mathrm{p}<.001$.

\section{The significant-interaction reflects the fact that}

- In general, the 7-year-olds asked more categorical and fewer single item questions on the posttests than did the 5-yearold subjects. However, the 5-year-olds who recelved direct training on the 20 Questions problem, or a combination of both 20 Questons and Listener training, asked as many categorical questions as did the T-year-old children on this task, $F(1,112)=.718, p>.05$. The 5 -year-olds who had been given Listener tralning alone improved their 20 Questions $\rightarrow$ in? 
performance from the pretest level, but not to the level achieved by the children. who were given direct training on the 20 Questions task, $F(1,112)=13.45$, p 4.001 . The $5-$ year-old control children who recelved practice on the tasks improved only marginaliy on the posttests, and were significantly poorer than the experimental group children, $F(1,112)=68.68, p<.001$. Among the 7-year-oid subjects, both training and practice conditions were effective in inproving their posttest performance on the 20. Questions task. Experimental and control subjects dy not differ signiflcantty, $F(1,112)=1.82, p>05$. "It should be noted ${ }^{*}$ however, that all of the children experienced some minimal training on the Iistener task during pretesting. At this time the children were given one example of a listener probliam: If they asked a single-item question it was explained that while their target fitted the speaker's description, so did several other targets. They were reminded that they could ask questions to clarify ambiguity. This orief experience which pointed out the existence of message amblguity may have influenced the performance of the. 7-year-old control children.

- In summary, both the targets-correot and type of. questions measures of 20 Questions performance are consistent. On the pretest, 7-year-olds asked more categorlcal and fewer single-item questions, and identified 
nore targets correctly than did the 5-year-olds. Children at both age levels became'more efficient in, their. inquiry strategies across the phases of testing. They asked fewer single-item and more categorical questions on the posttests. Consequently, their targets-correct scores increased. The 5-year-olds required training in order to inprove from the pretest to the posttests. Treatnent conditions which gave - them direct traiking on the 20 Questions problem were nost effective. The 7-year-olds improved their efficiency from the pretest to the posttests following any of the training conditions, or following a period of practice with the tasks. i.

\section{Listener Task}

Targets serrect. The mean'numer of targets correctly 1dentified on each of the listener tasks are presented in Table 5. The 1 istener task was a referential communication problem in which, the child. was required to fdentify a target referent on the basis of a speaker's verbal description. Each task consisted of four tridis. in which the speakens's message varfed in informational. agequacy, leaving either one, twor forf, or elght targots pos'sibly correct. A 2 (Age) x 4trieatment condition) $x$ $2($ Sex $) \times 3$ (Phase of Testing) $\times 3$ (Degree of Message ... Amb1guity) analyśs of variance was performed on these data: 
The data/in Table 5 show that when the speaker's message was unambiguous, and gave/all the information necessary to identify the target, children in all groups performed the listeper task accurately. Thus, thése data were not included in the analysis. The analysis revealed signiffcant main effects of age, $F(1,112)=36.11, p<.001$, treatment condition, $F(3,113)=.7 .54 ; p<1001$, and phase of testing, $F(2,224)=214.64, p<.001$; These main effects were 1ower order to the significant interactions of Treatment Condition $x$ Phase of Testing, $F(6,224)=5.57, p<.001$, and Age $x$ Sex $x$ Phase of Testing, $F(2,224)=3.23$, p <. 05 .

Inspection of the data in Table 6 reveals that the main effect of phase of testing is interpretable. All of. the children increased their targets-crrrect scores from the pretest to the immediate and delayed, postests. The main effect of age can also beg interpreted, In genèral, 7-yearold children identified more targets correctly than did the 5-year-old-children. There is one exception to this pattern which occurs in the 20 Questrongtraining group. On the immediate posttest, the 5-year-olds had slightly higher targets-correct scores than did the 7-year-olds in that condition.

If order to claryfy the Treatment $x$ Phase, and the Age $x$ Sex $x$ Phase interactions, separate analyses of variance were performed on the pretest and the posttest 
data. Age, sex, and treatment condition were factors in. both arialyses. Phase of testing was also a variable in the posttest analysis. The analysis of the pretest data revealed a șignificant main effect of age, $F(1,112)=7.72$, p<.01. This reflects the fact that the 7-year-olds ident 1 mod margets correctly than did the 5-year-olds on the pretest measure.

The analysis of the posttest data revealed significant main effects of age, $F(1,112)=29.06, p<.001$; and treatment condition, $F(3,112)=11.27, p<: 001$. Inspection of the data in Table 6 indicates that the 7 year-old subjects identified more targets correctly on the posttests tharidid the 5-year-olds, and that experimental subjécts at both ages identified more, targets correctly than . did control subjects.

The posttest analysis also revealed a significant Age $x$ Sex $x$. Phase of. Testing interaction, $F(1,112)=6.08$, p<.05, which was higher order to the signiflcant main effect. of phase of testing, $F(1,112)=31.74, p<.001$. The data in Table 7 indicates that the phas variable is interpretable. Al1 of the subjects improved their targets-correct score. from the limmediate to the delayed posttest. Inspection of the data in Table 7 also reveals that the significant: interaction primarily reflects the performance of the 7 year-old females on the immediate postest. They scored 
signifleantly higher than any of the other subjects at that time of testing, $F(1,224)=27.71, p<.001$.

Caterorical suestions. The data on the number of categorical questions asked during the listener tasks are presented in Tabile:8. As was defined above, a categorical question 1 s one which eliminated more than one item at a time-from the array of possibly correct targets. When performing the listener task, a child must ask categorical questions, following a speaker's ambiguous message in order to identify the target referent correctly. A single-item question represents a guess, and the chlld is scored as incorrect on that trial. The number of categorical questions required to identify the target depends on the degree of ambiguíty of the speaker's message. Thus; the child must ask one, two; or three questions, depending on. whether the speaker's message leaves two, four, dr eight 'possible alternatives correct. When the speaker's messabe is unambiguous, a child can identify the target referent with a single-1tem question. The data in Table 5 indicates that in this condition the children's identification of correct targets was very accurate. Also, when a child has narrowed down the number of possible alternatives in $a^{\circ}$. speaker's message by asking categorical questions, he/she can then identify the target with a single-item question. 
Since both the maximum and minimum number of single-item. questions that a child can ask on either correct or incorrect trials is one, the data on the number of singleitem questions asked does not provide any useful Information, and was not included in the analysis:

A 2(Age) $\times 4$ (Treatment Condition) $\times 2(\operatorname{Sex})$ 3 (Phase of Testing) $x$ (Degree- of Message Ambiguity) analysis of variance was performed on the data in Table 8 . This analysis revealed a signiflcant. Age $x$ Treatment Condition $x$ Phase, of Testing x Degree of Message Ambiguity interaction, $F(12,448)=2.05, p<.05$, which was higher order to the significant main effects of age, $F(1,112)=40.81$, p<.001, treatment condition, $F(3,112)=9.00, p<.001$, phase of testing, $F(2,224)=273.16, p<.001$, and degree of message anbiguity, $F(2,224)=2,224)=327,19, p<.001$, and the sigificant-interactions of Age $x$ Degree of Message Ambiguity, $F(2,224)=11.83$, p<.001, Treatment Condition $x$ Degree of Message Ambiguity, $F(6,224)^{\prime}=5.36$, p<.001,

- Treatment Condition $x$ Phase of Testing, $F(6,224)=6.20$, p<.001, Age $x$ Treatment Condition $x$ Phase of Testing, $F(6,224)=3.15 ; p<.01$, and Degree of Message Ambiguity $x$ Phase of Testing, $F(4,448)=67: 20, p<.001$. This analysis also seyealed a significant interaction of Age $x$ Sex $x$ Phase of Testing $x$ Degree, of Message Ambigutty, $F(4,448)=2.47$, p<.05. 
Inspection of the data in Table 8 indicates that onfy the diain effect of phase of testing can be interpreted. Subjects in all groups increased the number of categorical questions they asked from the pretest to the posttests. In order to clarify the Age $\dot{x}$. Treatment Condition $x$ Degree of Message Ambiguity $x$ Phase of Testing Interaction and the Age $x$ Sex $x$ Degree of Ambiguity $x$-Phase of Testing interaction, separate analyses of varlance were performed on the pretest. and posttest data. Age, sex, treatmento condition, and degree of message ambiguity were factors in both analyses. Phase of testing was also variable in the posttest. analysis.

The results of the pretest analysis revealed significant thain effects of age, $F(1,112)=15.41, p<.001$, and degree, of message anb1guity, $F(2,224)=5.86, p<.001$. These results reflect the fact that the 7 -year-olds asked more categorical questions on the pretest than did the 5year-olds, and that, in general, more categorical questions were asked at the higher levels of ambiguity.

The posttest analysis revealed significant interactions of Age $x$ Degree of Message Amb1guity, $F(2,224)=$ $10.31, p<.001, \mathrm{~g}$, $\mathrm{f}^{\mathrm{a}}$ Treatment Condition $x$ Degree of Ambiguity, $F(6,224)=5.82, p<.001$. These were higher order to the significant main effegts of age, $F(1,112)=25.48$, p<.001, treatment condition, $F(3,112)=12.91, p<.001$, and 
degree of message ambiguity, $F(2,224)=410.31, p<.001$. Inspection of the posttest average data in Table 8 reveals that the ma1n effects of treatment condition and degree of message ambiguity can be interpreted. Experimental group subjects at both age levels asked more categorical questions than did control group subjects: Also, all of the subjects increased the number of categorical questions they asked as the degree of ambiguity in the speaker's, message increased. The significant interactions of Age $\times$ Anbiguity and Treatment Condition $x$ Ambiguity primarily reflect the performance of the 5-year-old children in the control group. These children asked fewer categorical questions on the posttests than did any of the other groups, at all levels of message ambiguity, $F(1,112)=148.57, p<.001$, Both $5-$ and 7- year-old children in the other treatment conditions increased the number of categorical questions they asked on the posttests. However, the 5-year-olds who were given Listener training, or the combination of both Listener and 20. Queations training, and the 7-year-olds in the control condition showed less improvement in performance than did the 5-year-olds in the 20 Questions group and the 7 -yearolds in the three experimental groups, $F(1,112)=9.68$, p. $(.001)$.

The posttest analysis also revealed a significant interaction of Age $x$ Sex $x$ Phase of Testing $x$ Degree of 
Message Ambiguity, $F(2,224)=4.39, p<.05$, which was higher order to the significant main effect of phase of testing, $F(1,112)=13: 03, p<.001$. The data are presented in Table 9. This interaction reflects the fact that among the 5 year-old children, females asked more categorical questions than did the males on the second posttest, at the level of - message ambiguity. which left four possible alternatives cofreot. Among the 7-year-old chlldren, females asked more categorical questions than did the males on the first posttest at the level of message ambiguity which left four possible alternatves correct. The reason for these differences is not clear.

In summàry, the targets-correct data and the categorical questions data -were consistent. On the pretest measures the 7-year-olds asked more categorical questions than did the 5-year-olds, and thus identifled more targets correctly. On the immediate and gelayed postiests all children improved their performance; asking more categorical questions and 1dentifying more targets correctly: However, this improvement was marginal among the 5-year-old control children. The 5-year-olds who had been given 20 Questions: training performed almost as well as the 7-year-olds in that condition. As message ambiguity increased, children asked more categorical questions, as the task required. On both dependent measures, experimental group subjects performed 
more efficiently than did control group subjects. Thus, there were significant effects of training at both age levels on the listener task. 


\section{Rerceptual Scanning Task:}

The results of the perceptual scanning task supported the first hypothesis of this study. It had been pred-1cted that children at both age levels would be capable of conducting an exhaustive search of a stimulus array while attempting to locate targets which fitted a speaker's verbal description. In fact, both 5 - and 7 -year-old children made very fewerrors either of inclusion or exclusion on this. task. This finding has implications for the ilterature on children's referential communication sk11ls. It had been suggested by some researchers that an important reason why young listeners perform poorly on standard referential tasks 1s that they fail to detect ambiguities in a 'speaker's message. This was presumed to occur because they gidn't conduct an exhaustive search of the stimulus array, checking each potential target with the characteristics of the message. Instead, they terminated their search after the first appropriate target was located. "Since the chlldren in the present study generally did conduct an exhaustive search on the scanning task, they are clearly. capable in this regard.

Although it has been shown that children can search exhaustively, it is still a possibility that they sometimes 


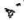

fail to d' ${ }^{3}$ so in the referential communication situation.

This possibility was addressed by Whitehurst and Sanpen- I schein (1978). They found that when 5-year-old sgeakers were given explicit, perceptuaí instructions to tell about how a referent "looked different" from the nonreferents, they were able to do so more efficiently than sưbjects who had not been given such explicit instructions. They concluded that chlldren know how to make comparisons but do not realize that comparison is relevant to effective

referential communication. It is not tureasonable to assume that the same generalization may apply to chlldren's 114tener performance: Although they can make an exhaústive search of a stimulus array when searohing for targets with

- specified characteristics, as in the scanning task reported in this study, they may fall to see that the istener role in referential communication also requires exhaustive scanning. Thus, knowing that chlldren can search exhaustively does not insure that they wili do so.

It is also possible' that children simply adopt a. different criterion for selecting a target in the perceptual scanning and ilstener tasks. On the listener task children, are instructed to look for onf target. Young children may interpret this to mean "any one targetn. Thus, they may terinl nate search following identiflcation of the first appropriate-target,without searching for others. In the 


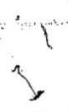

perceptual scanning task the child knows he/she is usually looking for more than one target, and thus keeps searching. Although incomplete scanning was infrequent on this task, it did contribute to errors made in some instances: A few of the chlldren résponded impulsivety following the message and did not scan carefuily. Thus, they terminated their search prenaturely. It is also possible that children made-errors because they misinterpreted the task requirements. Some of the children indicated puzzlement when the speaker's message required them to ydentify all eight of the - targets, or only one of the targets. The instructions. ("Polnt to all the pictures that show.,$"$ ) may have created, an expectation that they should identify less than eight or more than one of the targety. This was especially evident on the pretest trials. In these instances the children took longer to respond, and gave more ponverbal signs of confusion; seeming more thoughtful than impulsiye..

Iwenty Questions and Listener Tasios

The second hypothe'sis that this study was designed to test was also confirmed. It had been predicted that since the 20 Qúestions and listener tasks had many cognitive requirements in common, training children to perform either one of the tasks would generaflze to their performance on the other task. Children at both age levels who were 
trained on a modified version of the 20 Questions task were able to generalize the training to their performance on the listener task. Simllarly, children who were trained on a referentlal listener task were able to generalize the training to the 20 Questions task. It 1 s important to note that both Listener training and 20 Questions training involved direct instruction in the technique of asking categorical questions. The success of these training procedures in producing a high level of performance and cross-task seheralization supports the basic assumption that both the 20 Questions and Listener tasks can be viewed as information-seeking problems which are highly similar in their cognitive and task requirements. Correlational analyses between the training task, scores and the generalization task scores for subjects within age by group. cells might provide additional support for this assumption. However, such analyses were not carried out on the present data because the children's 20 Question scores on the posttests were too near celling.

Iwenty evestions. The children's pretest performance. on the modified 20 Questions task was consistent with that reported by previous investigators. When 5-year-old children were $\mathrm{g}$ iven, this task they asked very few categorical questions. Instead, they adopted a strategy of guesing, or asking single-item questions. Consequently, they correctly 
Identified very few of the targets within the permitted number of questions. The 7-year-old children asked significantly more categorical questions on the pretest and, thus, correctly identified more targets than did the younger children. However, they did not use this strategy reliably. These, data are consistent with the early report by Mosher and Hornsby (1966). They found that children between 6- and 8-years-old begin to acquire the strategy of asking categorical questions. These children tended to switch from categorical to single-itenquestions on/a given problem, a strategy labeled "pseudo-conștraint seeking" by Mosher and Hornsby.

Posttest performance indicated that 7 -year-olds given Listener training, 20 Questions training, or a combination of both types of training all performed at pasar ceiling level on the immediate posttest, and maintalued their level of performance on a follow-up test a week later. These children readily adopted the;strategy of using categorical instead of single-itgem questions to narrow in on the correct target. The 7-year-bids in the control group also performed at near celling level, their pecformance being only slightly poorer than that of the trained children. It' would seem that the abllity to ask categorical questions was in the repetolre of these children, and mere exposure to the task, either through training or practice 
was sufficient to elicit the strategy.

The 5-year-old children also improved; their 20 Questions posttest performance following training. Children who had been given 20 Questions training or the combination of 20 Questions and Listener training asked almost as many categorical questions and eprrectly identified as many targets as did the older children. They were also able to generalize the Listener training to their 20 Questions performance, : being only marginally less efficient in this condition. Howęver, 5-year-old children in the control group who recelved only practice with the tasks, showed only marginal improvement on the posttests.

The facility with which the younger children were able to acquire the categorical question strategy suggests that they already possessed the relevant sub-skills. (scanning, asking questions, classification) prior to: training. Exposure to training helped them to coordinate the components and to use them effioiently to solve 20 Questions problems. However, direct instruction was necessary for these children. Mere exposure to the task was insufficient to elicit the strategy.

This-posttest performance of the chlldren in both age groups is generally consistent with the existing 20 Questions 11terature. The subjects in this study, readily increased the number of categorlcal questions and decreased 


$$
3
$$

the number of single-item questions they asked following direct instructional feedback from the experimenter to do so. The older children were aiso able to adopt this strategy. following practice with the task. This finding is also consistent with the age norms reported by Mosher and Hornsby (1966) which indicated that at about eight years of. age, children begin to ask categorical questions spontấn-. eously. The results of this study-further indicate that adopting a strategy of asking categorical questions increases problem-solving efficiency. The chlldren identified more targets correctly following adoption of the appropriate strategy, and did so with the minimum number of questions. The effectiveness of asking categorical quest ions on problem solving efficiency has not been clearly demonstrated in the previous literature.

Listerer task. The results of this study also indicated that young chlldren can perform competently as. listeners in a referential communication task situation: When the speaker's message was fully informative, children at both age levels were able to correctly identify the referent. Their performance was near celling level without any training. This: is consistent with the results of other research and is yet another indication that young children can keep a speaker's message in working fímory while scanning a stimulus array in search of, a match, terminating. 

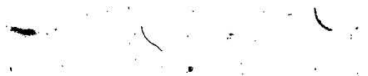

their sêarch only when it' has been 'located. However, when the message is fully informative there is no ambiguity to be Identified, so terminating search with the identification of the first match resuits in a correct choice.

In contrast, when the chiluren were given an ambiguous message on the pretest, their performance was poor. The pretest scores showed that very few categorical questions were asked and, consequently, very few target referents were correctly identified. Instead, children asked single-item questions, which reflected the use of a guessing strategy. The pretest performance of the 5-yearolds was significantly poorer than that of the 7 -year-olds, although the latter asked categorlcal questions linfrequentiy: These children guessed at the 1dentity of the correct referent in spite of having been forewarned that some of the messages would be unclear and that they could. ask questions of the speaker-if they were uncertain.

Thi's inadequate listener performance is typical of n.that observed by other researchers with children of this age. Two types of explahations have traditionaliy been. offered. The first is that children fall to complete the nesessary comparison activity needed to detect the ambiguity." in the message. As discusised above, this could occur either because the children were unable to complete the comparisons, or because of "metacommunicativen deficit 
whereby they fall to realize that in the referential communication task the speaker's message has to fit the target uniquely. Thus, they adopt a different standard for selecting the correct target. The second explanation is that children can make exhaustive comparisons and do detect the ambiguities, but do not realize that the next thing that they have to do is ask for more information. This could also be considered a problem in metacommunication. Since common observation indicates that young children can and do. ask questions, it may be that they, do not see the necessity of doing so in this particular situation. There is considerable evidence to support this latter explanation. Cosgrove and Patterson $(1977,1978)$ found that giving children a plan for effective listening which emphasized the importance of asking questions to resolve ambiguity produced a significant improvement in 11 stener performance of 6-, 8-, and 10-year-old chlldren, but hot in 4-year-olds. This pla was more effective than one which emphasized making comparisons. They concluded that the children were already making comparisons but needed to be aware of the follow-up strategy of asking quiestions, or of indicating in some manner, the need for more information. Similar conclusions were reached by other researchers (Meissner, 1978; Pratt \& Bates, 1982; Whitehurst \& Sonnenschein, 1983).

The results of the present study also support the

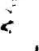


conclusion that getting children to ask questions is the critical skill needed to improve their listener performance on the referential task. In addition, the results of this. study indicated that children not only must be made aware of the need to ask questions, but specifically, that they should ask categorical questions: They need, to know not only when to ask questions, but also what type of questions to ask. "The posttest performance of children-in both age groups showed a significant improvement in listener performance following training procedures which provided them with direot instruction in the technique of asking categorical questróns. All chlldren asked fewer single-item questions', and identified more referents, correctiy following this training. The trained children maintained, and further improved their performance on a delayed postiest a week later. They also:asked more categorical, questions as the degree of message ambigulty increased. Children in control conditions who received only: practice remained significantiy poorer in their performance than did the experimental children." The poorer performance of the 7-year-old control children on the 11 stener task contrasts with their performance of the 20 Questions task. In the latter condition, mere exposure to the task through practice resulted in a significant improvement in their performance on the posttests. It should be noted however, that although 
the listener performance of these older children was inferior to that of their trained, peers, they did show more improvement on the posttests than did the 5-year-old control children.. This was especially evident on the delayed. posttest.

It is important to recall that as was the case with the 20 Questions task, the same training procedure, was presented to the children, in one of two different, contexts. Chifaren were elther trained to ask categorical questions in the context of a 20 Questions task or in the context of a listener task. For another gnoup these two contexts werecombined. The posttest results showed that children at both age levels were able to benefit from direct training on the listener task, but were also able to improve their listener performance following 20 Questions training.

Although teaching chilaren to ask categorical questis questions in either of these contexts was effective in improving listener performance, the younger children seemed to find it easier to generalize the technique of asking categorical questions following 20 Questions training. The 5-year-old children in this condition performed better than their peers, and as well as the 7 -year-old experimental children on the 11stener task. This somewhat unexpected finding may be attributable to the different information. processing demands of the two tasks. . Performance, of both 
the 20 Questions and Listener tasks required the children to scan, categorize and ask questions. However, performance of the Listener task also required that, the children check for ambiguity between the speaker's message and the characteristics of the targets in the array. Thus, the strategy of asking categorical questłons may have been more salient in the context of the 20 Questions training procedure: The 5year-olds, who were given listener training or the combined training also improved significantly on the posttests, as did the 7-year-old control children, but their performance was not as efficient' as that of the former groups The $5-$ year-old control children who recelved practice on the tasks showed only marginal improvement on the posttests. The significant training effects obtained with the 5-year-old children in this study contrasts with the results reported by other investigators who were Iess successful in demonstrating competent listener performance in children of this age (Cosgrove \& Patterson, 1977,1978; Ironsmith \& Whitehurst, $1978 \mathrm{a}, 1978 \mathrm{~b})$. Furthermore, the stimulus arrays used to evaluate performance in the present stydy were more complex than those used by other researchers who did report some training effects." Children in this study were, presented isth"eight item arrays which consisted of stimul1. that varied on three dimensions; with two values on each dimension (medium complexity). Host frequently, researchers 
have presented children with four item arrays consisting of stimuli that varied on two dimensions, with two values of each dimention ( $10 \mathrm{w}$ complexity). Some have used even simpler two item arrays. Although it was not a training study, Pattersion et al (1981) studied the effects of stimulus. complexity on comprehension monitoring in a lisfener task and reported that 5-and 7-year-old children did hot indicate the need for more information following an ambiguous message when presented with high and medium. complexity arrays, although the 7-year-olds did do so with low complexity arrays. Whitehurst and Sonnenschein $(1981$, 1983) found that 5-year-old children could be trained as listenars if they could point to a "bad message buttion" following a speaker's ambiguous message. However, the chlldren were not required to formulate any question to elicit the missing tinformation. The training procedure involved giving the child corrective feedback following an error, which pointed out that the speaker had not told how: the targets looked different, and that the child: must. have been guessing. Pratt and Bates (1982) found that 4-year-old children, trained with a verbal self-regulation procedure to Indicate that they "needed to ask a question", did so following a message containing an'ambiguous pronoun. The type of questions asked was not discussed in this study. The focus was on children's ability to monitor their own 


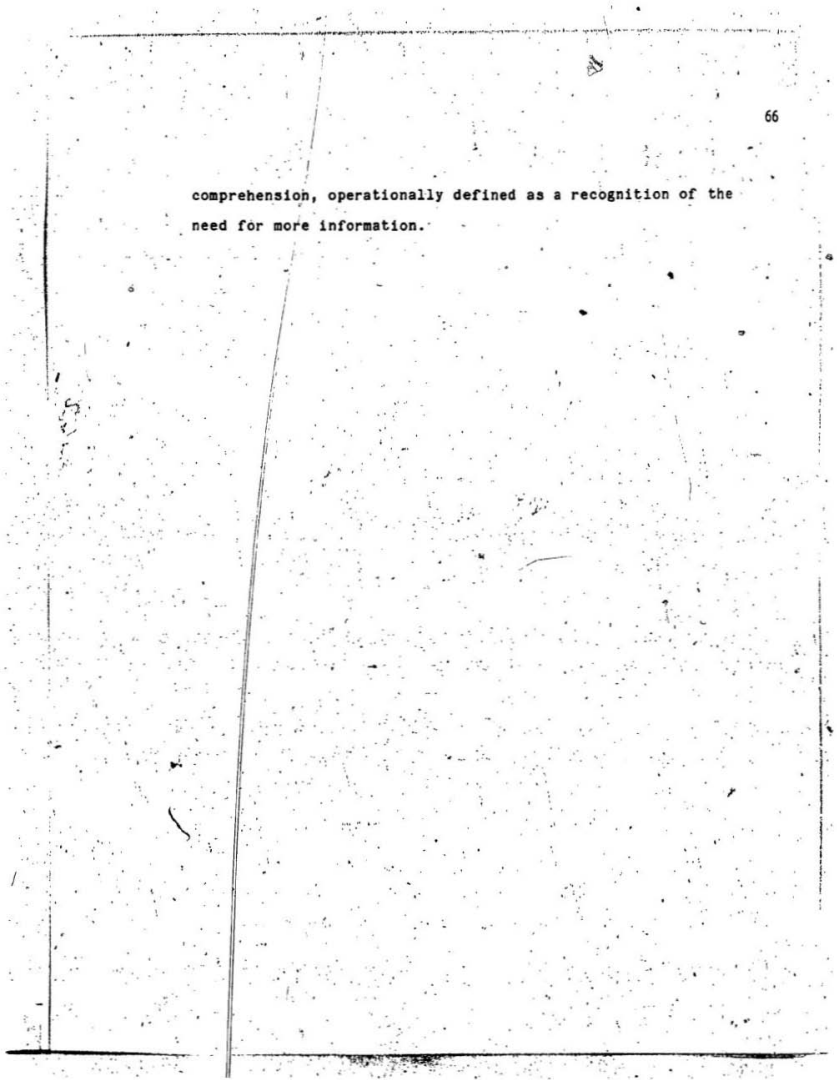


4 Concluston

The successful cross-task generalization demonstrated by children at both age levels indicates that, as predicted, the 20 Questions and referential listener tasks have similar requirements. These results support the conclusion that both tasks can be viewed as problems in information-seeking, the solution to which requires the child tomask categorical questions.

However, while they are highly similar, the two tasks are not isomorphic. Children at both age levels found the ilstener task to be somewhat more difficult than the 20 Questions task. The performance of all of the experimental group children, and that of the 7-year-old control chlldren, reached near celling level on the 20 Questions task by the first posttest. In contrast, performance on the istener task improved on both the first and second posttests, but did not approaç celling level in any of the groups: There are a number of reasons which might explain the discrepency In children's performance on these two tasks.. For example, observation of the children performing the listener task suggested that they found it to be puzzing. In natural conversation, aduíts do not deliberately give ambiguous messages to children. As Grice (1975) has argued,: reciprocal conversations usually require -1isteners to employ a cooperative principle, by which they assume that speakers 
seek to be informative, relevant, truthful, and clear.

Furthermore, when çonversational information is ambiguous, to guesss at' what the speaker means is usually an appropriate strategy. Their guess will generally be followed by feedback, which inforas them that they have thade a correct or an incorrect response. In the latter case, the adult w111 generally supply the missing information automaticaliy, the child does not have to request. it specifically. An incorrect guess certainly does not terminate the interaction as 1 t does in the referential task situation.

Ackerman (1978, 1981) has argued that young children have learned to respond to ambiguity/in natural conversational exchanges with a "performative" bias by which they feel under obligation to produce a referent if it is possible to do so. Thus, as long as the referent fits for almost fitsl the message, the child will-select it. Ackerman has shown however, that even 6-year-old children are sensitive to the fact that it is not always appropriate to select an ambiguoús referent, that in some contexts only a unique referent will do. Thus, children look to contextual variables, such as the speaker's intent, his/her degree of certainty or authority, and the net cost to the 11stener of $\therefore$ selecting an approximately correct target-versus continuing to search for a unique target, before responding to a message. In natural settings, understanding is not simply a 
function of decoding a message, as it is in referential comunication; but also of interpreting contextual variables.

Q The child in the referential listener situation has to realize the speaker's intent is that the target must fit the message uniquely, and that ambiguity has to be resolved by careful decoding of the message and by requesting additional information.

The enfectiveness of the training procedure used in the present study may be attributable to the explicit. Instructional feedback that was provided to the children. They were told that the appropriate response to an ambiguous message was to ask categorical questions, and not to simply take a guess. In this way, the children may have been relieved of the need to interpret an important contextual variable (1.e., the speaker's intent), and were thus able to focus their attention on decoding the message. The decoding process was perhaps facilitated by the presence of the perçeptual arrily which enhanced detection of the dimensions along which stimulf, could be conpared and contrasted, and along which ambiguity could occur. Consequently, asking - categoricai questions was 'not difficult under these' conditions. In comparison, there is never this problem with interpreting ambiguity in the 20 questions task: No messages are given by the speaker. The child knows that helshe has to elicit all the information necessary to solve

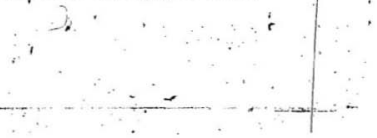


the problem. Thus, although solving the listener problem. may not seem to make greater task demands than solving the 20 questions problem, it may take children a little longer to adapt their usual listener behavior to cope with the ambiguity in the referential task.

It is also possible that, althou'gh young children can conduct an exhaustive search and comparison process as they did on the perceptual scanning task, they may not always do so on the listener task. It may be difficult for young children to remember on each trial that "the special one ${ }^{n}$, is unique, and that finding one target that fits the speaker's description does not mean that they should terminate their search. For example, as the chlldren in this study began to acquire the strategy of asking categorical questions during training, some of them used if inconsistently. They would sometimes ask one or two categorical questions, and, although the ambiguity of the speaker's message required that they ask one or two more, they would revert to singlejitem questions and fall to identify the target correctiy: It is possible, then, that the necessity of checking the message against each target, and rechecking the message with the target as each ren piece. of information is obtained, is an additional requirement that makes the 'listener task qenuinely more difficult than, and different from, the 20 Questions task. 


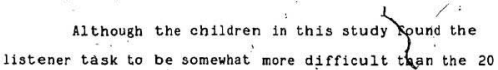
Questions task, tralning them to ask categorical questions improved their performance' on both tasks. Clearly', effective information- seeking is an important skill with potential application to the solution of a variety of

- problems. It is also posisible that the training procedures employed in this study might generalize to children's a performance as speakers in a referential communication task. Transfer from speaker to listener performanio, and vise versa, has been very difficult to demonstrate (Whitehurst \& Sonnenschein, 1983). This is a question for future research.

It might also be, useful to try to inprove the 11stener performance of preschool children by instructing them in the strategy of asking categorioal questions. While attempts to train referential listener skills in children of this age group have been uniformly unsuccessful, Denny et al (1979) found that 4-year-olds improved their 20 Questions performance following direct instructions in how to ask categorical questions. Furthermore, Pratt and Bates (1982) showed that 4-year-olds could be trained to indicate noncomprehension following an ambiguous message. This also is a question sor further research and is presently under investigation. 


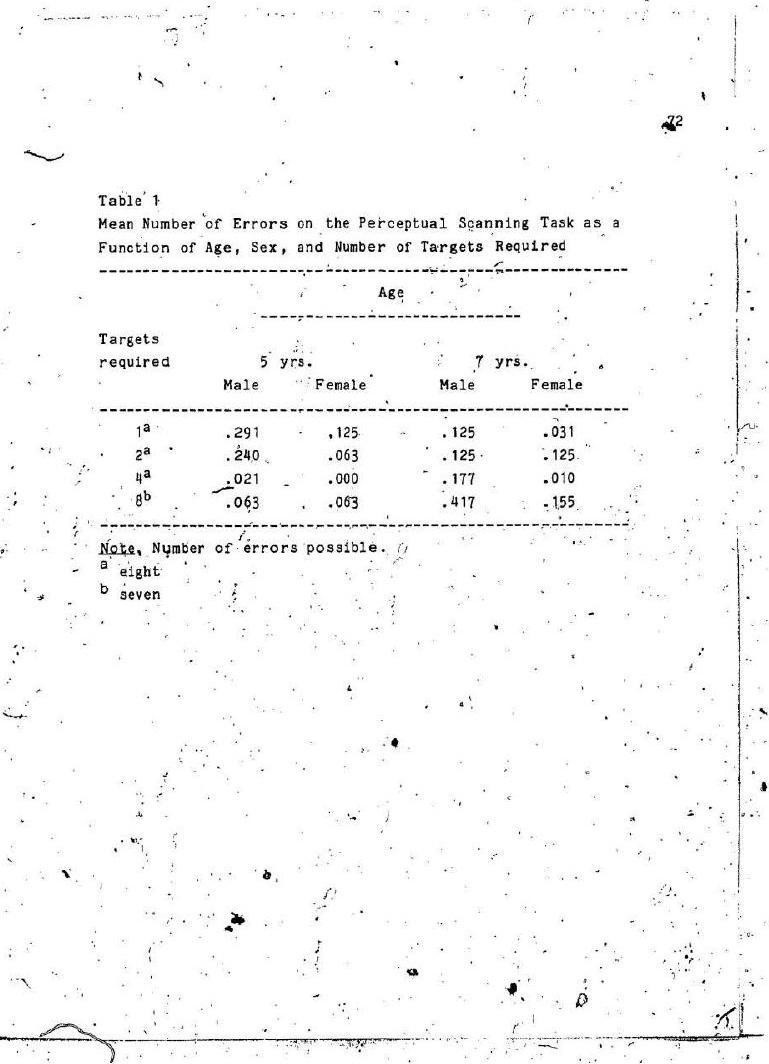


$\begin{aligned} & 4 \\ & 4\end{aligned}=$

, +

Table 2

Mean Number of Errors on the Perceptual Scanning Task as a

Function of the Phase of Testing and the Number of Targets Requified

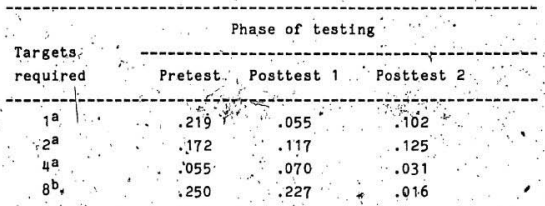

Note. Number of errors possible
a eight
b seven
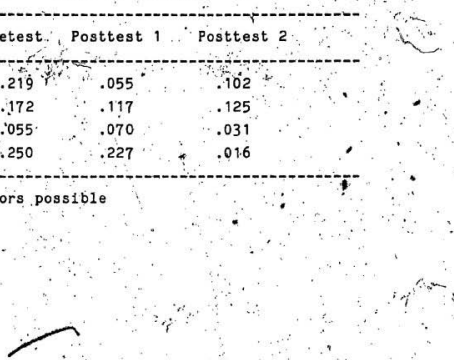

ty

$\therefore$

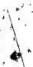




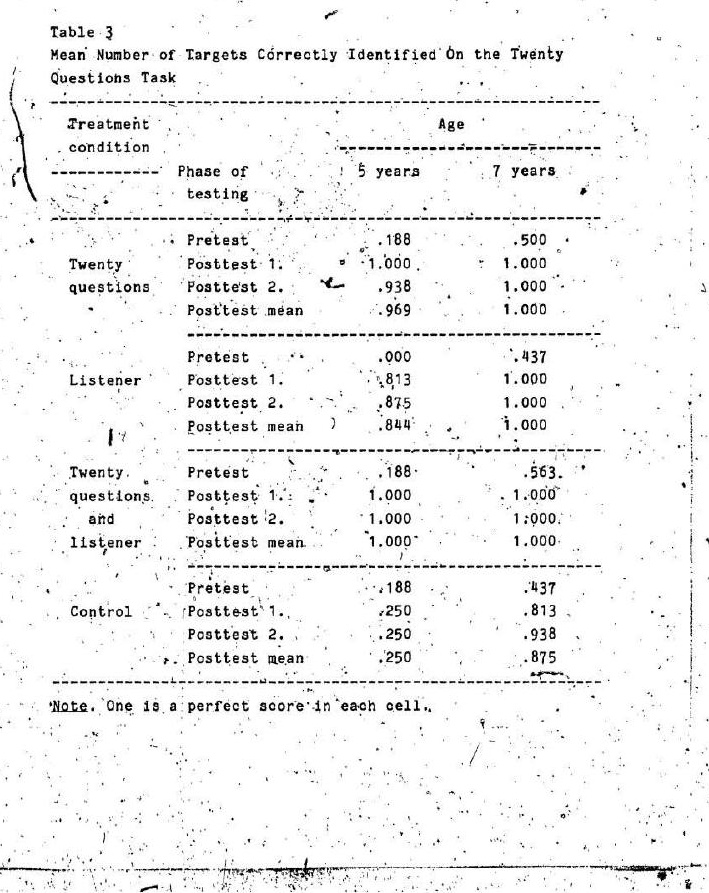


Táble 4

Mean Number of Categorical (C) and Single-Item (SI) Questions Asked on the Twentíl Questions Task

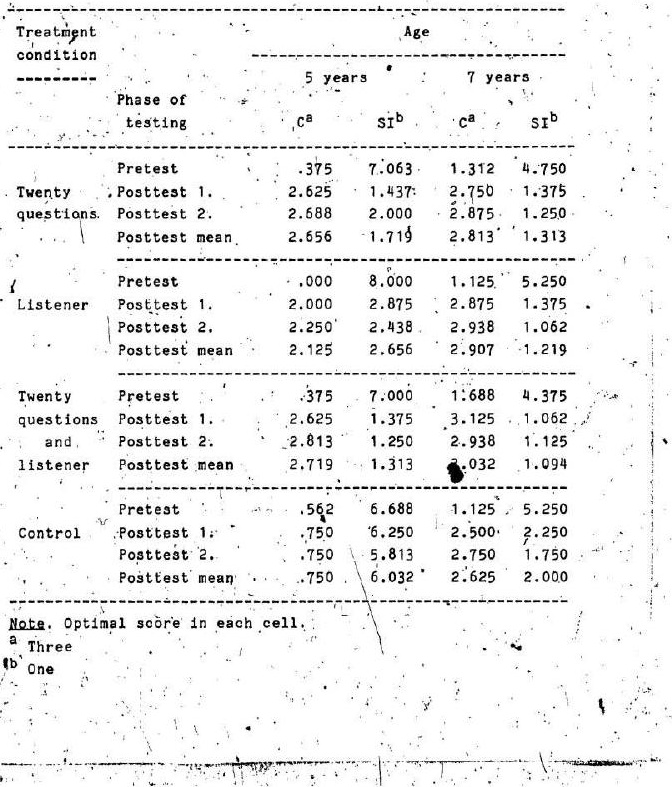


Table 5

Mean Number of Targets Identified Correctly on the Listener Task as. a. Function of Message Ambiguity.

Treat -

Age

ment

group

5 years

7 years

Pretest Posttests pretest posttests

$1 \div 2$ mean $\because 6 \quad 1$ 2 mean

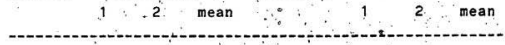

Ambig- :

uity

$\begin{array}{llllll}1 & 1.000 & 1.000 & 1.000 & 1.000 \quad .937 & 1.000 \quad 1.000^{\circ} .000\end{array}$

$\begin{array}{lllllllllllll}20 & 0 & 2 & .125 & .625 & .875 & .750 & .313 & .437 & .875 & .656\end{array}$

$\begin{array}{llllllllll}4 & .000 & .500 & .813 & .656 & .125 & .563 & .750 & .656\end{array}$

$\begin{array}{lllllllll}8 & .063 & .563^{\circ} & .688 & .625 & .313 & .625 & .875 & .750\end{array}$

$\begin{array}{llllllll}1 & .875 & 1.000 & 1.000-1.000 & 1.000 & 1.000 & 1.000 & 1.000\end{array}$

List- $2 \quad .000 \quad \begin{array}{lllllll}500 & .563^{\circ} & .531 & .525 & .813 & 1.000 \quad .906\end{array}$

eper $\begin{array}{lllllllll}4 . & .000 & .563 & .688 & .625 & .250 & .625 & .938 & .781\end{array}$

$\begin{array}{llllllllll}8 . & .000 ; & .500 & .688 & .594 & .187 & .750 & .813 & .781\end{array}$

‥

$\begin{array}{lllllllllll}20 & Q & 1 . & .938 & 1.000 & .938 & .969 & 1.000 & .938 & 1.000 & .969\end{array}$

and $2 \quad .000 \quad .688 \quad .625 \quad .656 \quad .250 .013 \quad .875 \quad .844$

list- $4 \quad .000 \quad 6500 \quad .563 \quad .531 \quad .250 \quad .938 \quad 1.000 \quad .969$

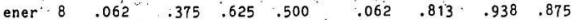

$\varepsilon_{4}$

\begin{tabular}{|c|c|c|c|c|c|c|c|c|}
\hline & $1: 1.000$ & 1,000 & .938 & .969 & .938 & $\therefore 938$ & 1.000 & .969 \\
\hline$n=$ & .062 & .187 & .250 & .219 & 438 & $\therefore 5 p 0$ & .813 & .656 \\
\hline 01 & 4. $\cdots .000$ & $: 125$ & .250 & .182 & .125 & .375 & .688 & .531 \\
\hline & .000 & .187 & .125 & .156 & .062 & .500 & $\therefore 750$ & .625 \\
\hline
\end{tabular}

Nete. One is a perfect score. Ambiguity levels 1, 2, 4, and 8 leave $1,2,4$, or 8 targets possibly correot, reapectively. 
Table 6

Mean Number of Targets Correctly Identified on the Listener Task as a Function of Age; Treatment, and Phase of Testing

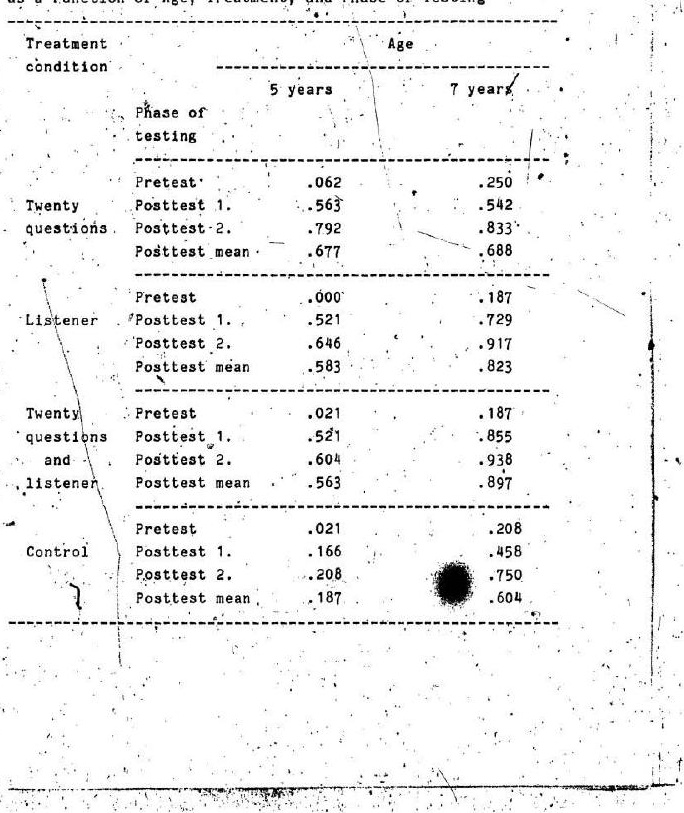


Table $7 \curvearrowleft$

Mean Number of Targets Correctly Identified on the Listener Iask as a Function of Age, Sex, and Phase of Testing

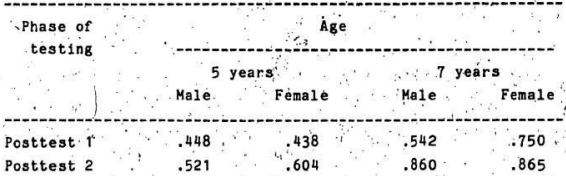

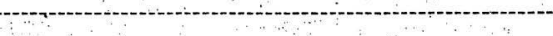


Table 8

Mean Number of Categorical Questions. Asked on the Listener Task as a Function of Ambiguity, Age, Treatment, and Phase

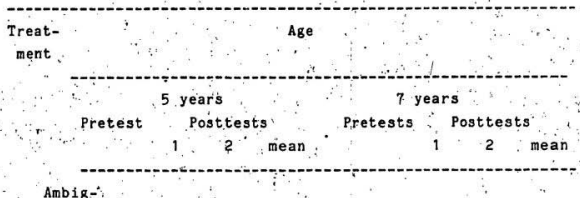

Ambig-:

uity.

$\begin{array}{rrrrrrrrrrr} & 2 & .125 & .625 & .938 & .781 & .938 & .438 & .500 & .875 & .688 \\ 20 & 4 & .188 & 1.375 & 1.625 & 1.500 & .563 & 1.438 & 1.688 & 1.563 \\ 1 & 8 & .188 & 2.375 & 2.625 & 2.500 & 1.188 & 2.438 & 2.687 & 2.563\end{array}$

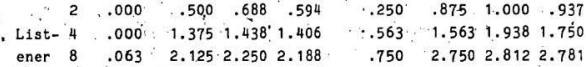

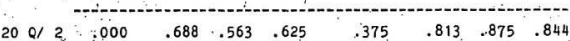

$\begin{array}{llllllll}\text { List- } 4 \quad .000 \quad 1.375 & 1.438 & 1.406 & .813 & 1.875 .2 .000 & 1.937\end{array}$

$\begin{array}{lllllllll}\text { ener } & 8 & .188 & 1.875 & 2.500 & 2.188 & .750 & 2.687 & 2.937 .2 .812\end{array}$

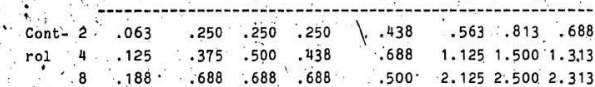

Note. Message ambiguity levels 2, 4, or 8 . leave two, four, or

iefght alternatives correct, respectively. Thus, one, two, or three questions, respectively, are needed to obtain the necessary information. 
Table 9

Mean Number of Categorical Questions Asked on the Listener Task as a Function of Age, Sex, Phase of Testing, and Degree of Ambiguity

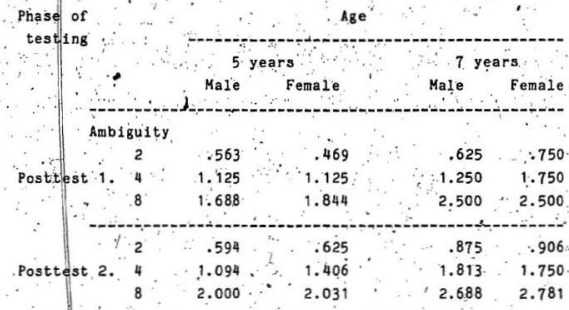

Note. For ambiguity levels 2, 4, and 8, the number of questions needed ta get the information necessary-for target identification is one, twg, or three, respectively.

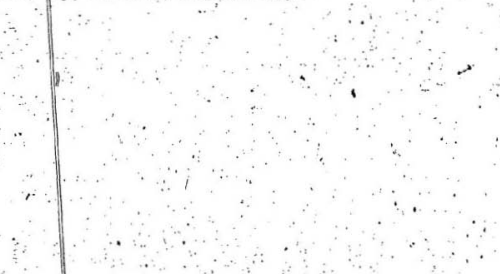


References,

Ackerman, B.P. (1979). Chlldren's understanding about definite descriptions: Pragmatic inference of the speaker's intent. Journal of Experimentaj chold Psychelegx, $28,1-17,47 \overline{2}-480$.

Ackerman, E.P. (1981). Performance bias in children's

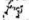

Interpretations of ambiguous réferential communi-

catións. Child Development, 52, 1224-1230.

Alvy, K.T. (1969): Relationshlp of age to children's

egocentric and cooperative communications, Journal of Genetie Psychelegy, 112, 275-286.

Asher, S.R. (1976). Children's ability to appraise their own and another person's communication performance. Develomental Psychology, 12, 24-32.

Asher, S.R: (1979), Referential communication. "In G. Whitehurst and B. Zimmertian (Eds.), The functions of language and sognition. New York: Academic Press. Asher, S.R. \& Wigfield, 'A. (1981), Training children's referential comunication skills.. In W.P. Dickson (Ed.); Chilidrén's óral communieation skills (pp105-. 126). New York: Academic Press.

Ảtkin, R., Bray, R., Dávison, M., Herzberger, S., Humphrey, L., \&elzer, U. (1977). Cross-lagged panel analysis of sixteen cognitive méasures at four grade levels. 
Child Development, 48, 944-952:

Beal, C.R., \&.Flavell, J.H. (1982). Effect of increasing the salience of message ambiguity on kindergarteners evaluations of communichative success and message adequacy. Developmental Paychology, 18, 43-48. Beal, C.R., \& Flavell, J.H. (1983). Young speakers') evaluations of their listeners' comprehensión in a referential communication task. Child Developient. 54 , $148-153$.

Bearison, D.J., \& Lévy, L.J. (1977). Children's comprehension of referential communication: Decoding ambíguous messages. Child Development, 48, 716-720. Bohannan, J.N., \&/Marquis, A.C. (1977): Children's control of aduit speech. child Development, 48, 1002-1008. Cosgrove, J.M., \& Patterson, C.J. (1977). Plans and the development of 11stendr skills. Developmental psychelegy, 13, 557-564.

X Cosgrove, J.M., \& Patterson, C.J. (1978). Ceneralization of training for children's listenèr skills. child Develooment, 49, 513-516.

Denney, D.R. (1972). Modéling and eliciting effécts upon conoeptual strategies. Ch1ld Development, $43,810-823$. Denney, D.R. $\left(1975^{\prime}\right)$. The effects of exemplary and cognitive models and self-rehearsal on children!'s interrogative strategies. Journal of Experimental Child Psychelegy. 
19, 476-488.

Dénney, D.R., Denney, N.W., \& Ziobrowski, M. (1973).

Alterations in the information processing strategies of young children following obsẹrvation of adult models. Develedmental Psychelezy, 8, 202-208.

Denney, N.W.; \& Connors, G. W. (1974). Altering the questioning, strategies of preschool children. child Development, $45,1108-1112$.

Denney, N.W., Denney, D.R. $\left(197^{\prime}\right)$. Modeling effects in the questioning strategies of the elderlef. Developmental Psycholegy, 10, 458 .

Denney, N.W., Jones; F.W., \& Krigel, S:H. (1972). Modifying the questioning strategies of young children and elderly adults with strategy modeling techniques. Human Develodment, $22,23-34$.

Dickson, W.P. (1974). The development of Iriterpersonal referential communication skills in young children using an interactional game device. (Doctoral dissertation, Stanford, University). Dissertation Abstracts International, 35, 3511-A.

Dickson, W.P., Hess, K.G., Miayke, N, \& Azuma, H. (1979). Referential, comminication accuracy between mother and child as a predictor of cognitive development in the

$\therefore$ United States and Japan. child Develeoment, 50, 53-59. Ditțman, A.T. (1972). Developmental factors in conver- 
sational behavior. Journal of Communication, 22,404$4 \dot{3}$.

Flave11, J.H. (1977). Cognitive development. Englewood

Cliffs, N.J.: Prentice-Hall.

Flavell, J.H., speer, J.R., Greên, F.L., \& August, D.L.

(1981). The development of comprehension monitoring and knowledge abbut communication. Monographs of the Society for Research in child Development, 46, (5, Serial No. 192).

Ford, W. \& olsion, D.: (1975). The elaboration of the noun phrase In children's descriptions of objects. Journal of Experimental child Psycholesy, 19, 371-382.

Glucksberg, S., Krauss, R. , \& Higgins, E.T. (1975). The development of referential communication skills.. In F.D. Hordwiti (Ed.), Review of child development research (Vol: 4, pp. 305-346): Chicago: University of Chicago Press.

Grice, H.P: (1975). Logic and conversation. In P. Cole \& J. Morgan "(Eds.), syntax and semantics (Vol. 3). New York: Seminar.

Ironsmith, M., \& Whitehurst, G.J. (1978a). The development of listener abilities in communication:, How children. deal with ambiguou's informantion; Child. Development, 49, 348-352.

Ironsmith, M., \& Whitehurst, G.J. (1978b). How children 
992.

Markman, E.M. (1979). Realizing that you don't understand:

Elementary school children's awareness of inconsist- . encies. Child Development, 50, 643-655.

Meissner, J.A,. (1978). Judgement "of' clue adequacy by kindergarten and grade two children, Develepmental Psychelogy, 14, 18-23.

Menig-Peterson, C.L..(1975). The modification of communicatiye behavior in preschool-aged children as a function of thie listener's perspective. Child Development, 46, 1015-10 18.

Mosher, F.A.; \& Hornsby, J,R. (1966). On asking questions. In J. Bruner, R. Oliver, \& P. Grefenfields (Ëds.); Studies in eggnitive growth. New York: Wiley.

Patterson, C..J., Cosgrove, J,M., \& O'Brien, R.G. $(1980)$ : Uonverbal indicants of comprehension and noncomp-: rehension in children. Developmental Psychology, $16, \cdots$ $38-48$.

Ratterson, C.J., \& Massad, C:M. '(1980). Facilitating referential commication among children: The listener fas teacher. journal of Experimental child Psychology, $29 ; 357-370$.

Pattérsón, C.J., Massad, C.M., \& Cosgnove, J.M. (1978): - Children's referential communioation: Comporients of plans for effective isteneng. Developmental Psychel- 


\section{esy, $14,104-106$.}

Patterson, C.J., O'Brien, C., Kister, M.C, Carter, DiB., \& Kotsonis, M.E. (1981) Development of comprehenston monitoring as a function of context. Dévelopmental Psychology, 17, 379-389.

Péarl, R., Donahue, M., \& Bryan, T. (1981). Children's responses to nonexplicit requests for clarification. Perceptual and peter Skdlis, 53, 919-925.

Peterson, C.L., Danner, F.W., Flavell, J.H. (1972). 5 Devèlopmential changes in children's response to three indications of gommunicative fallure child Development, $43,1463-1468$.

Pratt, M.W., \& Bates, K.R. (1982). Young editors:

Preschoolers evaluation and production of ambiguous messages. Developmental Psycholegy, 18, 30-42, .

Roberts, R.J., a Patterson, C.J. (1983): Perspective-tgking and referential communication: The question of correspondence reconsidered. Chlld Development, 54, $1005-1014$

Robinson, E.J.e (1981). The child s understanding of inadequate messages and communication failure: $A$.

-question of ignorance or egocentrism. In W.P. Dickson (Ed.), chtidren's oral communteation skduls (pp.167188). New York: Academ1c Press.

Robinson, E.J, Robinsol,W.P. (1976). Tho young oh1ld's 
understanding of communication. Dexdlopmental Psychelest. $12 ; 328-333$ :

Robinson E.J., \&obinson, W.P. (igT7a). Children's - explanations of communication fallure and the $\left\{\begin{array}{l}\text { Inadequacy of the, misunderstood message. Develogmental } \\ \text { Psychology, } 13,156-161 .\end{array}\right.$

Robinson, E.J., \& Robinson, W.P. (1977b). The child's understanding of 11 fe-like communication falitures: - Australlain Journal of Psychelogy, 29, 137-142.

Robinson, E.J., \& Robinson, W.P. (1977c). Development in the understanding of causes of success and fallure in verbal communication. Cognition, $5,363-378$.

Robinson E.J., Robinson, W.P. (1977d). The young child's explanation of communication fallure: A reinterpretation of results. Rerceptual and Metor Skills, 44 , $363-366$.

Robinson, E.J., \& Robinson;, W.P. (1977d). Children's explanations of communication fallure and the. Inadequacy of the misunderstood message. Developmental Psycholezy, 13, 156-161.

Robinson, E.J., \&obinson, W.P. (1978a). The relationship between children's explanation of communication failure and their ability to deliberately give bad messages. British Journal of Soeial and clinical Psyahelogy, 17, 219-225. 
Robinson, E.J., \& Robinson, W.P. $(1978 \mathrm{~b})$. The roles of egocentrism and of weakness in comparing in ch11dren's explanations of communication faillure. Jeurnal ef, Experimental Psychelogy, 26, 147-160:

Robinsion, E.J, Robinson, W.P. (1982). The advancement of ch1ldren's referent1al communication,sk111s: The role of metacognitive guidance. International journai of Behavieral Develomenta, 5, 329-255.

Robinson, E.J., \& Rob1nson, W.P.. (1983a). Children's uncertainty about the interpretation of ambiguous messages. Leurnal of Expertmential child Psychology, 36, 81-96.

Robinson, E.J., \& Robinson, W.P. (1983b). 'Communication and metacommunication: Quality of children's instructions. - In relation to judgements about the adequacy of instructions and the locus of responsibility for communication fallure. Journal of Experimental child Psychology, 36, 305-320.

Rósenberg, S., \& Cohẹn, B.D. (1966). Réferential processes of speakers and 11 steners. Psychelegical Reviex, 73, $208-23,1$.

Sachs, J:, Devin, J. (1976). Young ohlldren's use of ageappropriate speeoh styles, Jeurnal of Ch1ld Language, 3. $81-98$.

Schm1dt, C.R., A.Paris, S.G. (1984). The development of 
verbal communication skilis in children. Advances/in $\therefore$ shild develepment and behavior, 18, 1-47.

Shatz, M. (1977), The relation'ship between cognitive $\therefore$ procesfesand the development of communication skills: In C.B. Keasey (Ed.), Nebraska symoesium en motivation. Lincoln: University of Nebraska.

Shatz, M. (1978). On the development bf communicative understanding: An early strategy for interpreting and responding to miessages. Cognitive Psycholory, 10, 271301 .

Shatz, M. Gelman, R. (1973). The development of communipation skills: Modification in the speech of young children as a function of the listener. Monographs of the Soclety for Research in child Development, 38, (5, Serial No. 152).

S1egler, R.S. (1977). The twenty questions game as forn of problem solving. Chyld Development, 48, 395-403; Singer, J.B. Flavel1, J.H. (1981). The development of knowledge about communication: Children's evaluations : of explicitly ambiguous messages. Child Development, $\because \quad 52,1211-1215$.

Snow, L.E. (1972). Mothers' speech to ohildren learning language. Child Development, 43, 549-565.

Sonnensche1n, S. $(1980)$. The development of communication:

When a bad model makes a good teacher. Jeurnal of 
development of young chlldren's awareness of $\log 1 \mathrm{cal}$ Inconsistenceis. Journal of Experimental chlid Psychelegy, 36; 97-108.

Van Hekken, J., Vergeer, $M$, \& Harris, p. $(1980)$ : Ambiguity of reference and listener reaction in a naturalistic setting. Journal of Child hanguage, I, 555-563.

Warren-Leubeeker, A., Bohannon, J.N. (1983). The effects: of verbal feedback and 11 stener type on the speech of presohool ohildren. Journal of Experimental Child

- Psycholosy, 32, 540-548.

Wellman, H.M. \& \&empers, J.D. (1977). The naturalistic - communicative abilities of two-year-olds. child

- Develepment, 48, 1052-1057.

Whitehurst, G.J. (19.76). The development of comunication: Changes with age and nodeling. Chlld Development, 47, 473-482.

Whitehursit, G.J., \& Sonnenschein, S. (1978). The development of communication: Attribute variation reads to contrast fallure. Journal of Experimental Chlid Psycholory, 25, 490-504.

Whitehurst, G.J., \& Sorinenschein, S. (1981). The development" of Informative messages in referential communication: Knowing when versus knowing how (pp. 127-142), In. Wíp. Dickson (Ed.), Children's oral communication skilis.' New York: Aoaden10 Press iq 


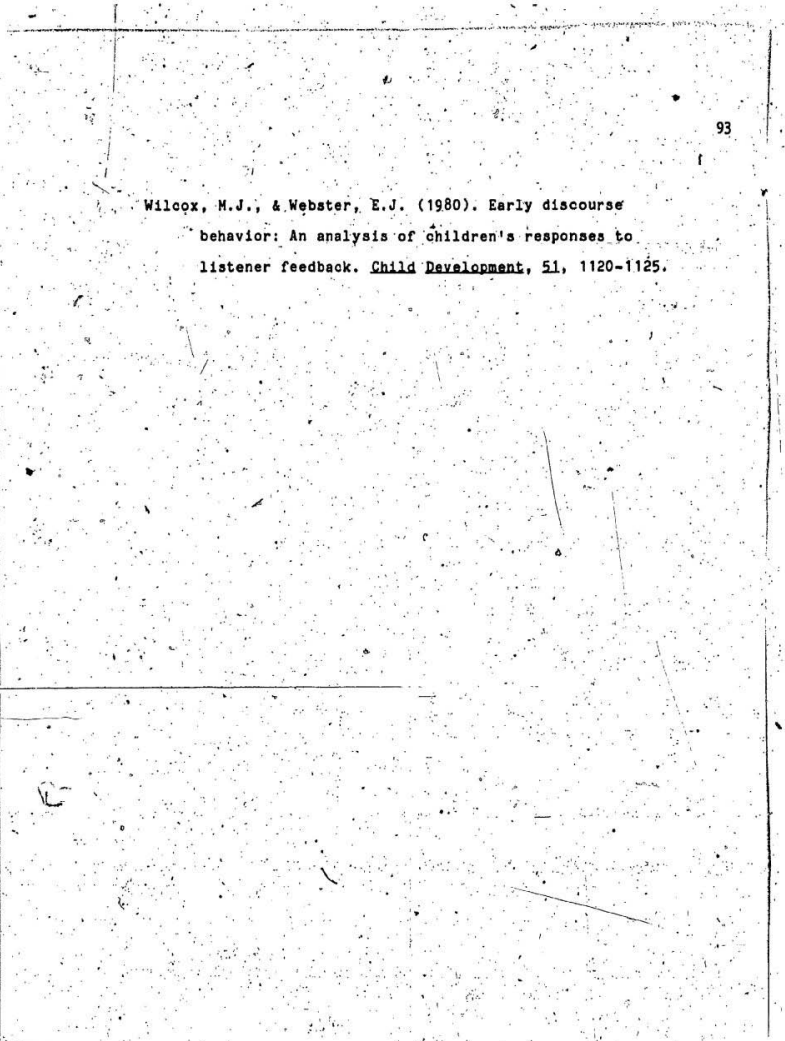

\section{behavior: An analysis of children's responses to} 11stener feedback. Child Development, 51, 1120-1125. 


